\title{
Dynamic Response of Bridge Subjected to Eccentrically Moving Flexible Vehicle: A Semianalytical Approach
}

\author{
R. Lalthlamuana and S. Talukdar \\ Department of Civil Engineering, Indian Institute of Technology Guwahati, Guwahati 781039, India \\ Correspondence should be addressed to S. Talukdar; staluk@iitg.ernet.in
}

Received 2 July 2013; Revised 8 January 2014; Accepted 8 March 2014; Published 5 May 2014

Academic Editor: Peijun Xu

Copyright (C) 2014 R. Lalthlamuana and S. Talukdar. This is an open access article distributed under the Creative Commons Attribution License, which permits unrestricted use, distribution, and reproduction in any medium, provided the original work is properly cited.

\begin{abstract}
Dynamic response of a single span bridge subjected to moving flexible vehicles has been studied using a semianalytical approach. The eccentricity of vehicle path giving rise to torsional motion of the bridge has been incorporated in the approach. The bridge surface irregularity has been considered as the nonhomogeneous process in spatial domain. A closed form expression has been derived to generate response samples corresponding to each input of roughness profile to form an ensemble. Thereafter, averaging across the ensemble has been carried out at each time step to determine mean and standard deviation of bridge and vehicle response. Further, dynamic amplification factor (DAF) of the bridge response has been obtained for several combinations of bridge-vehicle parameters. The study reveals that structural bending modes of vehicle can significantly reduce dynamic response of the bridge. The eccentricity of vehicle path and flexural/torsional rigidity ratios plays a significant role in dynamic amplification of bridge response.
\end{abstract}

\section{Introduction}

The dynamic effect resulting from the passage of vehicles is an important problem generally encountered in the bridge design. The irregularity or unevenness of the bridge pavement surface is the main cause of exciting the vehicle which in turn imposes a time varying load as it travels along the span of the bridge. Starting from the year 1922, various theoretical and experimental studies have been conducted to understand the dynamic behavior of bridge subjected to moving load. A review of literature on the said topic starting from basic formulation with moving mass has been published by Fryba [1] and Yang et al. [2] in their books with detailed discussion on the formulation and its limitations. Earlier researchers have considered vehicle as a moving mass on the bridge, either neglecting their inertia effect or incorporating the same. Although researchers have revealed various dynamic characteristics for practical applications, modern bridges of slender cross-section and larger span do not actually reflect true behavior when moving mass problems have been solved. The deformation of bridge can cause significant change in dynamic forces at the contact point of the vehicle wheel.
Realizing these facts, numerous studies have been conducted considering bridge-vehicle a coupled system, with consideration of stiffness and damping parameters of suspension systems. Biggs [3], Fryba [4], and Wen [5] are some of the earlier authors who considered vehicle as single lumped mass system having only bounce motion or a rigid system with bounce and pitch motion. A three-dimensional heave-pitchroll model has been investigated by Yadav and Upadhyay [6] to find the response of railway tracks on elastic subgrade. Vehicle models with seven and twelve degrees of freedom were developed by Wang et al. [7] according to H20-44 and HS20-44 which are major design vehicles in the American Association of State Highway and Transportation Officials (AASHTO). However, analyses of vehicle motions were confined to rigid modes only. Kou and de Wolf [8], Cheung et al. [9], and Marchesiello et al. [10] have studied the vibrational behavior of multispan continuous bridge by adoption of beam or isotropic plate model. The effect of moving mass or rigid standard vehicle models on the bridge response was examined. Yin et al. [11] investigated lateral vibration of high pier bridge subjected to moving vehicle. In addition to employment of three-dimensional rigid vehicle model, 
special attention was given to the modeling of tyre with a three-dimensional linear spring and a rectangular contact surface. Other notable works in bridge-vehicle interaction dynamics that include various dynamic properties of rigid vehicle have been reported by Chen and Cai [12], Law and Zhu [13], Zhang et al. [14], and Green and Cebon [15]. Marchesiello et al. [16] studied the interaction of multispan continuous bridges modeled by isotropic plates with multidegree of freedom vehicles moving at constant speed. Theoretical modes of plate vibration have been obtained with the help of Rayleigh-Ritz approximate method. Prestressed concrete single track railway bridges, consisting of several box girders, were studied by $\mathrm{Chu}$ et al. [17] in which they considered each girder to share equal loads and modelled as a beam. Rail irregularities are modeled using power spectral density function. Various works on bridge-vehicle interaction on multispan bridges have been reported by Huang et al. [18], Wang [19], and Ichikawa et al. [20]. Numerical techniques for solving the finite element model with rigid vehicle have been adopted. Other important works which include complexity in bridge model are that of horizontally curved girder [21, 22]. Analytical methods were employed to solve bridge dynamic problem subject to moving mass taking effect of centrifugal force. Effect of vehicle braking has been included in study of vehicle-bridge interaction problem by Kishan and TraillNash [23] and Radley and Traill-Nash [24].

Interests in research on bridge-vehicle interaction dynamics are still growing because of several complexities in modeling and uncertainties in excitation. In the last decade, researchers have undertaken more and more complex problems and attempted to solve by newer methodology taking into consideration support flexibility and nonuniform cross-section [25]. A vehicle-track-bridge interaction element considering vehicle's pitching effect has been developed by Lou [26]. Experimental results and their comparison with finite element model analysis of vehiclebridge interaction problem have been presented by Brady et al. [27]. Rigid model of vehicle has been considered in the study to determine set of critical velocity associated with peaks of dynamic amplification factor. Multiple resonance response of railway bridge has been investigated by Yau and Yang [28]. A vehicle-bridge interaction process has been simulated with MATLAB Simulink by Harris et al. [29] to find out bridge-friendly damping control strategy with a tractor semitrailer vehicle model. Very recently, some interesting studies of bridge-vehicle or road-vehicle coupled dynamics include stochastic numerics and discrete integration schemes for digital simulation of road-vehicle system by Wedig [30], application of spectral stochastic finite element by $\mathrm{Wu}$ and Law [31], and use of spectral matrix operator for direct solution of stochastic coupled differential equations by Kozar and Malic [32]. Those studies have significantly improved the understanding of complex problem in vehicle-bridge interactions. However, vehicle model has been assumed as lumped masses with rigid link connected by suspension elements exhibiting various discrete degrees of freedom. In most of the studies, numerical integration and Monte Carlo simulation techniques have been used. In the modern days, characteristics of vehicles have greatly changed due to incorporation of larger pay load and for increasing demand of traffic. In the past, vehicles have been modeled by a rigid $2 \mathrm{D}$ or $3 \mathrm{D}$ system having degrees of freedom in bounce, pitch, and roll. However, due to long and slender vehicle plying frequently over the bridges, there is a need to consider flexibility in the vehicle model and to examine the effect of flexible modes of vehicle on the dynamics of bridge. This aspect of bridge-vehicle dynamic interaction is not adequately addressed in the literature. With this in mind, present study has been conducted to find out the response statistics of single span bridge due to movement of flexible vehicle along an eccentric path. By the term "flexible vehicle," it is understood here that flexural modes have been included in addition to rigid body modes. The bridge has been considered to be under independent transverse bending as well as under torsional excitation arising out of the eccentric path of the vehicle. Nonhomogeneous profile of deck surface has been incorporated in the study by considering a deterministic mean surface superimposed by zero mean random process. Such formulation can take care of defects in surface finishing, construction joints, potholes, bump, approach slab settlement, and so forth. Bridge-vehicle system equations are expressed in statespace form and decoupled at each time step using complex eigenvalue analysis. Closed form expression has been derived for state vectors for each sample input of bridge profile to form the ensemble of response. Finally, averaging across the ensemble has been carried out to determine mean and standard deviation of the response quantities. In present approach numerical integration can be avoided to generate response samples, which can save considerable amount of computational time. The results obtained from present approach have been validated by numerical simulation and available experimental results from the literature. The effect of vehicle velocity on the response and combined effect of several vehicle-bridge parameters on dynamic amplification factor (DAF) have been examined.

\section{Mathematical Model}

The bridge-vehicle model has been shown in Figure 1. The bridge has been modeled as a uniform beam with simply supported end conditions. The mass, stiffness, and damping are assumed to be uniform along the span of bridge. Due to eccentricity of the vehicle path, the bridge is subjected to flexure as well as torsion. The bridge deck is uneven which has been realized as nonhomogeneous process in spatial domain. This is represented by a function $h(x)$.

2.1. Equation of Motion of Vehicle. Vehicle body has been idealized as Euler-Bernoulli beam of length $l_{v}$. The behavior of suspension systems consisting of spring and dashpot is assumed as linear. The governing differential equation of motion of the vehicle deflection can be expressed as

$$
E_{v} I_{v} \frac{\partial^{4} z(u, t)}{\partial u^{4}}+C_{v} \frac{\partial z(u, t)}{\partial t}+m_{v} \frac{\partial^{2} z(u, t)}{\partial t^{2}}=f_{v}(u, t)
$$




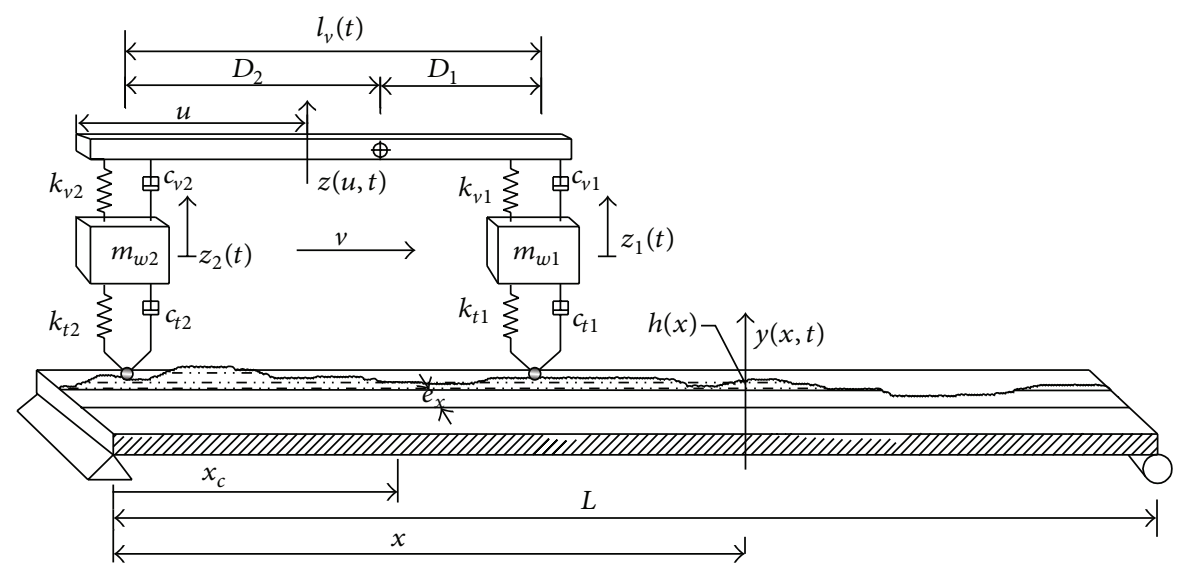

FIGURE 1: Bridge-vehicle model.

in which $m_{v}, E_{v} I_{v}$, and $C_{v}$ denote the mass per unit length, flexural rigidity, and viscous damping per unit length of the vehicle body and $z(u, t)$ represents vertical deflection of the vehicle body measured at location $u$ from the reference point (taken at the left end of the vehicle) at time instant $t$. The impressed vertical force on the vehicle body is given by

$$
\begin{aligned}
f_{v}(u, t) & \\
= & {\left[k_{v 1}\left\{z(u, t)-z_{1}(t)\right\}+c_{v 1}\left\{\dot{z}(u, t)-\dot{z}_{1}(t)\right\}\right] } \\
& \times \delta\left(u-u_{1}\right) \\
& +\left[k_{v 2}\left\{z(u, t)-z_{2}(t)\right\}+c_{v 2}\left\{\dot{z}(u, t)-\dot{z}_{2}(t)\right\}\right] \\
& \times \delta\left(u-u_{2}\right),
\end{aligned}
$$

where $u_{1}$ and $u_{2}$ represent the location of the attachment point of vehicle suspension from the reference point; $z_{1}$ and $z_{2}$ denote the vertical displacement of front and rear wheel masses respectively. $k_{v 1}$ and $k_{v 2}$ are the front and rear vehicle suspension stiffness, respectively; $c_{v 1}$ and $c_{v 2}$ represent damping for vehicle front and rear suspension, respectively, $\delta$ represents Dirac delta function with the property

$$
\int_{-\infty}^{\infty} f(x) \delta\left(x-x_{1}\right) d x=f\left(x_{1}\right) .
$$

The equation of motion for the front unsprung mass is given by

$$
\begin{aligned}
& m_{1} \ddot{z}(t)_{1}+k_{t 1}\left\{z_{1}(t)-y\left(x_{1}, t\right)-h\left(x_{1}\right)\right\} \\
& +k_{v 1}\left\{z_{1}(t)-z\left(u_{1}, t\right)\right\}+c_{v 1}\left\{\dot{z}_{1}(t)-\dot{z}\left(u_{1}, t\right)\right\} \\
& \quad+c_{t 1}\left[\dot{z}_{1}(t)-\frac{D}{D t}\left\{y\left(x_{1}, t\right)+h\left(x_{1}\right)\right\}\right]=0 .
\end{aligned}
$$

The equation of motion for the rear unsprung mass is given by

$$
\begin{aligned}
& m_{2} \ddot{z}_{2}(t)+k_{t 2}\left\{z_{2}(t)-y\left(x_{2}, t\right)-h\left(x_{2}\right)\right\} \\
& +k_{v 2}\left\{z_{2}(t)-z\left(u_{2}, t\right)\right\}+c_{v 2}\left\{\dot{z}_{2}(t)-\dot{z}\left(u_{2}, t\right)\right\} \\
& +c_{t 2}\left[\dot{z}_{2}(t)-\frac{D}{D t}\left\{y\left(x_{2}, t\right)+h\left(x_{2}\right)\right\}\right]=0,
\end{aligned}
$$

where $m_{1}$ and $m_{2}$ are front and rear wheel mass, respectively; $k_{t 1}, k_{t 2}$ are front and rear suspension stiffness respectively; and $c_{t 1}, c_{t 2}$ are front and rear suspension damping, respectively. $h\left(x_{1}\right)$ and $h\left(x_{2}\right)$ represent the nonhomogeneous deck profile under the front and rear wheels, respectively. $y\left(x_{1}, t\right)$ and $y\left(x_{2}, t\right)$ are bridge displacements under front and rear wheels, respectively, at any instant of time t. $z\left(u_{1}, t\right)$ and $z\left(u_{2}, t\right)$ represent vehicle body deflection at the front and rear wheels position at any instant of time $t . u_{1}$ and $u_{2}$ are the location of wheel from the end of the vehicle body. Coriolis forces that arise due to rolling of wheel on the deflected profile of the bridge have been considered in the equation of motion using total derivative operator $D / D t$ (with $D y / D t=$ $(\partial y / \partial x)(\partial x / \partial t)+\partial y / \partial t)[1,33]$

2.2. Equation of Motion of Bridge. It is assumed that, for symmetrical cross-section (symmetrical about vertical axis), bending and torsion of the bridge would be independent under vertically applied live load. Thus governing differential equation of motion of the bridge in flexure can be expressed as

$$
E_{b} I_{b} \frac{\partial^{4} y(x, t)}{\partial x^{4}}+C_{b} \frac{\partial y(x, t)}{\partial t}+m_{b} \frac{\partial^{2} y(x, t)}{\partial t^{2}}=f_{b}(x, t)
$$

in which $m_{b}, E_{b} I_{b}$, and $C_{b}$ represent the mass per unit length, flexural rigidity, and viscous damping per unit length of 
bridge. The impressed vertical force $f_{b}(x, t)$ on the bridge due to vehicle interaction is given by

$$
\begin{aligned}
f_{b}(x, t) & \\
=- & {\left[k_{t 1}\left\{z_{1}(t)-y(x, t)-h(x)\right\}\right.} \\
& \left.\quad+c_{t 1}\left\{\dot{z}_{1}(t)-\frac{D}{D t}[y(x, t)+h(x)]\right\}\right] \\
\times & \delta\left(x-x_{1}\right) \\
- & {\left[k_{t 2}\left\{z_{2}(t)-y(x, t)-h(x)\right\}\right.} \\
& \left.+c_{t 2}\left\{\dot{z}_{2}(t)-\frac{D}{D t}[y(x, t)+h(x)]\right\}\right] \delta\left(x-x_{2}\right) \\
- & \left\{m_{1}+\frac{1}{2} m_{v} l_{v}\right\} g \delta\left(x-x_{1}\right)-\left\{m_{2}+\frac{1}{2} m_{v} l_{v}\right\} g \\
\times & \delta\left(x-x_{2}\right) \\
+ & m_{1} \frac{D^{2}}{D t^{2}}[y(x, t)+h(x)] \delta\left(x-x_{1}\right) \\
+ & m_{2} \frac{D^{2}}{D t^{2}}[y(x, t)+h(x)] \delta\left(x-x_{2}\right),
\end{aligned}
$$

where $g$ is the acceleration due to gravity. The governing differential equation of the bridge in torsion can be written as

$$
G_{b} J_{b} \frac{\partial^{2} \gamma(x, t)}{\partial x^{2}}-C_{b T} \frac{\partial \gamma(x, t)}{\partial t}-I_{b} \frac{\partial^{2} \gamma(x, t)}{\partial t^{2}}=f_{T}(x, t),
$$

in which $I_{b}, G_{b} J_{b}, C_{b t}$, and $\gamma(x, t)$ represent the mass moment of inertia per unit length, torsional rigidity, distributed viscous damping to rotational motion, and torsional function of bridge, respectively. $J_{b}$ is torsional constant, and $G_{b}$ is the shear modulus of beam material. $f_{T}(x, t)$ is the torque produced in the bridge cross-section due to eccentric loading which is given by

$$
\begin{aligned}
& f_{T}(x, t) \\
& =-\left[k_{t 1}\left\{z_{1}(t)-y(x, t)-h(x)\right\}\right. \\
& \left.\quad+c_{t 1}\left\{\dot{z}_{1}(t)-\frac{D}{D t}[y(x, t)+h(x)]\right\}\right] \\
& \times e_{x} \delta\left(x-x_{1}\right) \\
& -\quad\left[k_{t 2}\left\{z_{2}(t)-y(x, t)-h(x)\right\}\right. \\
& \left.\quad+c_{t 2}\left\{\dot{z}_{2}(t)-\frac{D}{D t}[y(x, t)+h(x)]\right\}\right] \\
& \times e_{x} \delta\left(x-x_{2}\right)
\end{aligned}
$$

$$
\begin{aligned}
& -\left\{m_{1}+\frac{1}{2} m_{v} l_{v}\right\} g e_{x} \delta\left(x-x_{1}\right) \\
& -\left\{m_{2}+\frac{1}{2} m_{v} l_{v}\right\} g e_{x} \delta\left(x-x_{2}\right) \\
& +m_{1} \frac{D^{2}}{D t^{2}}[y(x, t)+h(x)] e_{x} \delta\left(x-x_{1}\right) \\
& +m_{2} \frac{D^{2}}{D t^{2}}[y(x, t)+h(x)] e_{x} \delta\left(x-x_{2}\right)_{x} \delta\left(x-x_{2}\right) .
\end{aligned}
$$

The parameter $e_{x}$ in (9) denotes the eccentricity of vehicle wheels from the centre line of bridge deck.

2.3. Bridge Deck Roughness. In the present study we introduce a roughness, which is nonhomogeneous in space even though vehicle velocity is constant, by adopting the following relation:

$$
h(x)=h_{m}(x)+\sum_{s=1}^{N} \varsigma_{s} \cos \left(2 \pi \Omega_{s} x+\theta_{s}\right),
$$

where $h_{m}(x)$ is a deterministic mean which represents construction defects, expansion joints, created pot holes, approach slab settlement, expansion joints, development of corrugation, and so forth; $\varsigma_{s}$ is the amplitude of cosine wave; and $\Omega_{s}$ is the spatial frequency $(\mathrm{rad} / \mathrm{m})$ within the interval $\left[\begin{array}{ll}\Omega_{L} & \Omega_{U}\end{array}\right]$ in which power spectral density is defined. $\Omega_{L}$ and $\Omega_{U}$ are lower and upper cut-off frequencies. The deck roughness is a Gaussian process [34] with a random phase angle $\theta_{s}$ uniformly distributed from 0 to $2 \pi$. $N$ is the number of terms used to build up the road surface roughness. The parameters $\varsigma_{s}$ and $\Omega_{s}$ are computed as

$$
\begin{aligned}
\varsigma_{s} & =\sqrt{2 S\left(\Omega_{s}\right) \Delta \Omega}, \\
\Omega_{s} & =\Omega_{L}+\left(s-\frac{1}{2}\right) \Delta \Omega, \\
\Delta \Omega & =\frac{\left(\Omega_{U}-\Omega_{L}\right)}{N},
\end{aligned}
$$

in which $S\left(\Omega_{s}\right)$ is the power spectral density function $\left(\mathrm{m}^{3} / \mathrm{rad}\right)$ taken from [35] modifying the same with addition of one term in denominator so that the function exists when $\Omega \rightarrow 0$ :

$$
S(\Omega)=S\left(\Omega_{0}\right) \times \frac{\Omega^{2}{ }_{0}}{\Omega_{s}{ }^{2}+\Omega^{2}{ }_{L}} .
$$

In the above equation, $\Omega_{0}=1 / 2 \pi \mathrm{rad} / \mathrm{m}$ has been taken. The spatial frequency $\Omega(\mathrm{rad} / \mathrm{m})$ and temporal frequency $\omega$ $(\mathrm{rad} / \mathrm{s})$ for the surface profile are related to the vehicle speed $V(\mathrm{~m} / \mathrm{s})$ as $\omega=\Omega V$. In the present study, vehicle forward velocity has been assumed as constant.

2.4. Discretization of Flexible Vehicle Equation of Motion. As mentioned earlier vehicle body has been modeled as free-free 
beam which has two rigid modes and $n_{v}$ number of elastic modes. It can be shown that when the translation of the mass centroid and the rotational motion about the mass centroid are considered, the two motions are orthogonal with respect to each other and with respect to the elastic modes [36]. Thus total displacement of these rigid body degrees of freedom and elastic modes can be described by

$$
z(u, t)=\sum_{j=-1}^{n_{v}} \phi_{v j}(u) \eta_{j}(t),
$$

where $\phi_{v j}(u)$ is the vehicle mode shapes; the subscript $v$ denotes vehicle; $\eta_{j}(t)$ is the time dependent generalized coordinate; $j$ is the mode number; $j=-1,0$ are taken to denote rigid body translatory and pitching mode; $j=$ $1,2,3, \ldots, n_{v}$ represent elastic mode sequence of free-free beam; and $n_{v}$ is the number of significant modes of flexible vehicle body. Thus two rigid modes can be written as

$$
\begin{aligned}
\phi_{-1} & =1, \\
\phi_{0} & =u-D_{2},
\end{aligned}
$$

where $D_{2}$ is a distance of vehicle centre of gravity from the trailing edge as given in Figure 1.

The elastic bending modes of free-free beam for $j=$ $1,2,3, \ldots$ are given by [37]:

$$
\begin{aligned}
\phi_{v j}= & \sin \left(\alpha_{j} u\right)+\sinh \left(\alpha_{j} u\right) \\
& +\beta_{j}\left[\cos \left(\alpha_{j} u\right)+\cosh \left(\alpha_{j} u\right)\right] \\
\beta_{j}= & \frac{\cos \left(\alpha_{j} l_{v}\right)+\cosh \left(\alpha_{j} l_{v}\right)}{\sin \left(\alpha_{j} l_{v}\right)+\sinh \left(\alpha_{j} l_{v}\right)},
\end{aligned}
$$

where corresponding nondimensional frequency parameters $\alpha_{j} l_{v}$ can be related to circular natural frequency as

$$
\omega_{v j}=\alpha_{j}^{2} \sqrt{\frac{E_{v} I_{v}}{m_{v} l_{v}^{4}}} .
$$

Substituting (13) in (1) and multiplying both sides of the equation by $\phi_{v k}(u)$ and then integrating with respect to $u$ from 0 to $l_{v}$ along with orthogonality conditions, the equation of motion can be discretized as

$$
\ddot{\eta}_{j}(t)+2 \xi_{v j} \omega_{v j} \dot{\eta}_{j}(t)+\omega_{v j}^{2} \eta_{j}(t)=Q_{v j}(t),
$$

where $j=-1,0,1,2, \ldots$

Generalized force $Q_{v j}(t)$ in the $j$ th mode acting on the vehicle is given as

$$
Q_{v j}(t)=\frac{1}{M_{v j}} \int_{0}^{l_{V}} f_{v}(u, t) \phi_{j}(u) d u,
$$

in which generalized mass $M_{v j}$ in the $j$ th mode is given by

$$
M_{v j}=\int_{0}^{l_{v}} m_{v} \phi_{v j}^{2}(u) d u .
$$

Making use of (2) and (13) in (17) and integrating the expression using the property of Dirac delta function, one has the following expression for generalized force:

$$
\begin{aligned}
& Q_{v j}(t) \\
& =\frac{1}{M_{v j}}\left[k_{v 1}\left\{z_{1}(t)-\sum_{j=-1}^{n_{v}} \phi_{j}\left(u_{1}\right) \eta(t)\right\} \phi_{j}\left(u_{1}\right)\right. \\
& +c_{v 1}\left\{\dot{z}_{1}(t)-\sum_{j=-1}^{n_{v}} \phi_{j}\left(u_{1}\right) \dot{\eta}(t)\right\} \phi_{j}\left(u_{1}\right) \\
& +k_{v 2}\left\{z_{2}(t)-\sum_{j=-1}^{n_{v}} \phi_{j}\left(u_{2}\right) \eta(t)\right\} \phi_{j}\left(u_{2}\right) \\
& \left.+c_{v 2}\left\{\dot{z}_{2}(t)-\sum_{j=-1}^{n_{v}} \phi_{j}\left(u_{2}\right) \dot{\eta}(t)\right\} \phi_{j}\left(u_{2}\right)\right] \text {. }
\end{aligned}
$$

It may be mentioned that infinite number of modes are possible in continuous system considered in the present study. However, for practical implementation only first $n_{v}$ modes of vehicle body have been included.

2.5. Discretization of Bridge Equation of Motion. Using first $n_{b}$ number of bridge bending modes, the bridge deflection in flexure be written as

$$
y(x, t)=\sum_{k=1}^{n_{b}} \phi_{b k}(x) q_{k}(t),
$$

where subscript $b$ represents bridge, $\phi_{b k}(x)$ is the flexural mode of the beam for simply supported boundary condition corresponding to natural frequency, and $\omega_{b k}$ and $q_{k}(t)$ are generalized coordinates in $k$ th mode [37].

Now, substituting (21) in (6) and multiplying both sides of the equation by $\phi_{b j}(x)$ and then integrating with respect to $x$ from 0 to $L$ with the use of orthogonality conditions, the equation of motion can be discretized in normal coordinates as

$$
\ddot{q}_{k}(t)+2 \xi_{b k} \omega_{b k} \dot{q}_{k}(t)+\omega_{b k}^{2} q_{k}(t)=Q_{b k}(t),
$$

where $k=1,2,3, \ldots, n_{b}$.

The generalized force $Q_{b k}(t)$ in the $k$ th mode of bridge in flexure is given as

$$
Q_{b k}(t)=\frac{1}{M_{b k}} \int_{0}^{L} f_{b}(x, t) \phi_{b k}(x) d x,
$$

in which generalized mass $M_{b k}$ in the $k$ th mode is given by

$$
M_{b k}=\int_{0}^{L} m_{b} \phi_{b k}^{2}(x) d x .
$$


The generalized force in the $k$ th of mode of bridge transverse vibration has been worked out as

$Q_{b k}(t)$

$$
\begin{aligned}
&=-\frac{1}{M_{b k}}\left[k_{t 1}\left\{z_{1}(t)-\sum_{k=1}^{n_{b}} \phi_{b k}\left(x_{1}\right) q_{k}(t)-h\left(x_{1}\right)\right\}\right. \\
& \times \phi_{b k}\left(x_{1}\right) \\
&+k_{t 2}\left\{z_{2}(t)-\sum_{k=1}^{n_{b}} \phi_{b k}\left(x_{2}\right) q_{k}(t)-h\left(x_{2}\right)\right\} \\
& \times \phi_{b k}\left(x_{2}\right) \\
&+c_{t 1}\left\{\dot{z}_{1}(t)-V \sum_{k=1}^{n_{b}} \phi_{b k}^{\prime}\left(x_{1}\right) q_{k}(t)\right. \\
&\left.-V \sum_{k=1}^{n_{b}} \phi_{b k}\left(x_{1}\right) \dot{q}_{k}(t)-V h^{\prime}\left(x_{1}\right)\right\}
\end{aligned}
$$$$
\times \phi_{b k}\left(x_{1}\right)
$$$$
+c_{t 2}\left\{\dot{z}_{2}(t)-V \sum_{k=1}^{n_{b}} \phi_{b k}^{\prime}\left(x_{2}\right) q_{k}(t)\right.
$$$$
\left.-V \sum_{k=1}^{n_{b}} \phi_{b k}\left(x_{2}\right) \dot{q}_{k}(t)-V h^{\prime}\left(x_{2}\right)\right\}
$$$$
\times \phi_{b k}\left(x_{2}\right)
$$$$
-\left\{m_{1}+\frac{1}{2} m_{v} l_{v}\right\} g \phi_{b k}\left(x_{1}\right)
$$$$
-\left\{m_{2}+\frac{1}{2} m_{v} l_{v}\right\} g \phi_{b k}\left(x_{2}\right)
$$$$
\times m_{1}\left\{\sum_{k=1}^{n_{b}} \phi_{b k}\left(x_{1}\right) \ddot{q}_{k}(t)\right.
$$$$
+2 V \sum_{k=1}^{n_{b}} \phi_{b k}^{\prime}\left(x_{1}\right) \dot{q}_{k}(t)
$$$$
\left.+V^{2} \sum_{k=1}^{n_{b}} \phi_{b k}^{\prime \prime}\left(x_{1}\right) q_{k}(t)+4 V h^{\prime \prime}\left(x_{1}\right)\right\}
$$$$
\times \phi_{b k}\left(x_{1}\right)
$$$$
+m_{2}\left\{\sum_{k=1}^{n_{b}} \phi_{b k}\left(x_{2}\right) \ddot{q}_{k}(t)\right.
$$

$$
\begin{aligned}
& +2 V \sum_{k=1}^{n_{b}} \phi_{b k}^{\prime}\left(x_{2}\right) \dot{q}_{k}(t) \\
& +V^{2} \sum_{k=1}^{n_{b}} \phi_{b k}^{\prime \prime}\left(x_{2}\right) q_{k}(t)
\end{aligned}
$$

$$
\begin{array}{r}
\left.+4 V h^{\prime \prime}\left(x_{2}\right)\right\} \\
\left.\times \phi_{b k}\left(x_{2}\right)\right],
\end{array}
$$

in which $(\cdot)$ denotes time derivative. Repeating the similar steps, the discretized bridge equation for torsion in normal coordinates can be expressed as

$$
\begin{array}{r}
\ddot{\gamma}_{l}(t)+2 \xi_{T l} \omega_{T l} \dot{\gamma}_{l}(t)+\omega_{T l}^{2} \gamma_{l}(t)=Q_{T l}(t) \\
\left(l=1,2,3, \ldots, n_{T}\right),
\end{array}
$$

where $n_{T}$ represents number of bridge torsional modes considered and $\omega_{T l}$ and $\xi_{T l}$ are the natural frequency and modal damping coefficient of the $l$ th mode in torsion, respectively. The generalized torque in the $l$ th mode is given by

$$
Q_{T l}(t)=\frac{1}{M_{T l}} \int_{0}^{L} f_{T}(x, t) \phi_{T l}(x) d x .
$$

The torsional natural frequency $\omega_{T l}$ and corresponding mode $\phi_{T l}$ for the given simply supported boundary conditions for no warping restrains have been taken from [37]. The generalized mass moment of inertia $M_{T l}$ in the $l$ th mode is given by

$$
M_{T l}=\int_{0}^{L} I_{b} \phi_{T l}^{2}(x) d x
$$

The generalized torque in the $l$ th mode can be expressed as

$$
\begin{aligned}
& Q_{T l}(t) \\
& =-\frac{e_{x}}{M_{T l}}\left[k_{t 1}\left\{z_{1}(t)-\sum_{l=1}^{n_{T}} \phi_{T l}\left(x_{1}\right) \gamma_{l}(t)-h\left(x_{1}\right)\right\}\right. \\
& \times \phi_{T l}\left(x_{1}\right) \\
& +k_{t 2}\left\{z_{2}(t)-\sum_{l=1}^{n_{T}} \phi_{T l}\left(x_{2}\right) \gamma_{l}(t)-h\left(x_{2}\right)\right\} \\
& \times \phi_{T l}\left(x_{2}\right) \\
& +c_{t 1}\left\{\dot{z}_{1}(t)-V \sum_{l=1}^{n_{T}} \phi_{T l}^{\prime}\left(x_{1}\right) \gamma_{l}(t)\right. \\
& \left.-V \sum_{l=1}^{n_{T}} \phi_{T l}\left(x_{1}\right) \dot{\gamma}_{l}(t)-V h^{\prime}\left(x_{1}\right)\right\}
\end{aligned}
$$




$$
\begin{aligned}
& \times \phi_{T l}\left(x_{1}\right) \\
& +c_{t 2}\left\{\dot{z}_{2}(t)-V \sum_{l=1}^{n_{T}} \phi_{T l}^{\prime}\left(x_{2}\right) \gamma_{l}(t)\right. \\
& \left.-V \sum_{l=1}^{n_{T}} \phi_{T l}\left(x_{2}\right) \dot{\gamma}_{l}(t)-V h^{\prime}\left(x_{2}\right)\right\} \\
& \times \phi_{T l}\left(x_{2}\right) \\
& -\left\{m_{1}+\frac{1}{2} m_{v} l_{v}\right\} g \phi_{T l}\left(x_{1}\right)-\left\{m_{2}+\frac{1}{2} m_{v} l_{v}\right\} \\
& \times g \phi_{T l}\left(x_{2}\right) \\
& \times m_{1}\left\{\sum_{l=1}^{n_{T}} \phi_{T l}\left(x_{1}\right) \ddot{\gamma}_{l}(t)+2 V \sum_{l=1}^{n_{T}} \phi_{T l}^{\prime}\left(x_{1}\right) \dot{\gamma}_{l}(t)\right. \\
& \left.+V^{2} \sum_{l=1}^{n_{T}} \phi_{T l}^{\prime \prime}\left(x_{1}\right) \gamma_{l}(t)+4 V h^{\prime \prime}\left(x_{1}\right)\right\} \\
& +m_{2}\left\{\sum_{l=1}^{2} \phi_{T l}^{n_{T}} \phi_{T k}^{\prime \prime}\left(x_{2}\right) \ddot{\gamma}_{l}(t)+2 V \sum_{l=1}^{n_{T}} \phi_{T k}^{\prime}\left(x_{2}\right) \dot{\gamma}_{l}(t)+4 V h^{\prime \prime}\left(x_{2}\right)\right\} \\
& \times \phi_{T l}\left(x_{1}\right) \\
& +
\end{aligned}
$$

\section{Method of Solution}

The system of (4), (5), (17), (22), and (26) is coupled second order ordinary differential equations. In general for continuous system like the ones (vehicle and bridge) presented in the paper infinite number of modes exist. However, for practical applications, modes have to be truncated to a finite size. Let $n_{v}, n_{b}$, and $n_{T}$ be number of significant modes of vehicle motion, bridge flexural, and torsional vibration, respectively. The number of coupled equations becomes $n=2+n_{v}+n_{b}+$ $n_{T}$. The system equations can be expressed in matrix notation as

$$
[M]\{\ddot{r}(t)\}+[C]\{\dot{r}(t)\}+[K]\{r(t)\}=\{F(t)\},
$$

where $\{r(t)\}=\left\{\eta_{1}(t), \eta_{2}(t), \ldots, \eta_{n v}(t), z_{1}(t), z_{2}(t), q_{1}(t)\right.$, $\left.q_{2}(t), \ldots, q_{n b}(t), \gamma_{1}(t), \gamma_{2}(t), \ldots, \gamma_{n T}(t)\right\}^{T}$ is the response vector, $\{F(t)\}$ is the generalized force vector and, $[M],[\mathbf{C}]$, and $[K]$ are system mass, damping, and stiffness matrix, respectively.

The system equation can be cast into a $2 n$-dimensional first order differential equation of the following form:

$$
\{\dot{p}(t)\}+[A]\{p(t)\}=\{P(t)\},
$$

where

$$
\begin{gathered}
\{p(t)\}=\left\{\frac{\dot{r}(t)}{r(t)}\right\}, \quad\{P(t)\}=\left\{\frac{[M]^{-1}\{F(t)\}}{\{0\}}\right\}, \\
{[A]=\left\{\frac{[M]^{-1}[C]}{-[I]} \frac{[M]^{-1}[K]}{[0]}\right\} .}
\end{gathered}
$$

This form is suitable for bridge-vehicle interaction problems, since suspension damping is not small and diagonalization of damping matrix as in case of Rayleigh's damping may not be fully convincing. $[I]$ is an identity matrix and $\mathbf{0}$ a null vector or matrix. Let the eigenvalues of the state matrix $\mathbf{A}$ be $\alpha_{1}, \alpha_{2}, \alpha_{3}, \ldots, \alpha_{2 n}$ and the corresponding eigenvectors $\{\mathbf{u}\}^{1}$, $\{\mathbf{u}\}^{2},\{\mathbf{u}\}^{3}, \ldots,\{\mathbf{u}\}^{2 n}$. The modal matrix is defined as

$$
[U]=\left[\{u\}^{1}\{u\}^{2}, \ldots,\{u\}^{2 n}\right] .
$$

The eigenvalues are assumed to be distinct. Thus one has

$$
[U]^{-1}[A][U]=\text { diagonal }\left[\alpha_{1}, \alpha_{2}, \alpha_{3}, \ldots, \alpha_{2 n}\right] \text {. }
$$

Let us assume

$$
\{p\}=[U]\{v\} .
$$

Using linear transformation in (35), the state-space equations in decoupled form can be written as

$$
\dot{v}_{j}(t)+\alpha_{j} v_{j}(t)=R_{j}(t), \quad j=1,2,3, \ldots, 2 n,
$$

with

$$
R_{j}=\sum_{k=1}^{n} u_{j s}^{\prime} \sum_{s=1}^{n} m_{s k}^{\prime} F_{k}(t)
$$

$u_{j s}^{\prime}$ denotes elements in the inverse of the matrix $[U]$ and $m_{s k}^{\prime}$ the elements in the inverse of matrix $[M]$.

The general solution of (36) in Stieltjes integral [38] form may be expressed as

$$
v_{j}(t)=X_{0 j} \exp \left(-\alpha_{j} t\right)+\int_{-\infty}^{\infty} H_{j}(\omega, t) d S\left[F_{k}(\omega)\right],
$$

where $X_{0 j}$ are constants of integration to be determined from the initial conditions. $H_{j}(\omega, t)$ is the transient frequency response function given by [38]

$$
H_{j}(\omega, t)=\frac{1}{-i \omega+\alpha_{j}}\left[\exp (-i \omega t)-\exp \left\{-\alpha_{j}\left(t-t_{0}\right)\right\}\right] \text {. }
$$

It can be seen that as $t_{0} \rightarrow-\infty$, for the positive real part of $\alpha_{j}, H_{j}(\omega, t)$ approaches the limiting value (1/ $\left.i \omega+\alpha_{j}\right) \exp (-i \omega t)$. This is the characteristics of stable dynamic system. Using (37) and (39) in (38), the response in generalized normal coordinate may be expressed as

$$
\begin{aligned}
r_{m}(t)= & \sum_{j=1}^{2 n} u_{m+n, j} X_{0 j} \exp \left(-\alpha_{j} t\right) \\
+ & \sum_{j=1}^{2 n} u_{m+n, j} \sum_{s=1}^{n} u_{j s}^{\prime} \sum_{k=1}^{n} m_{s k}^{\prime} \int_{-\infty}^{\infty} H_{j}(\omega, t) d S\left(F_{k}(\omega)\right) \\
& m=1,2,3, \ldots, n .
\end{aligned}
$$


The first term of (40) represents homogeneous solution of the system equation due to initial condition and the second term of the equation may be written using the limiting value of transient frequency response function

$$
\begin{aligned}
r_{P m}(t)= & \sum_{j=1}^{2 n} u_{m+n, j} \sum_{s=1}^{n} u_{j s}^{\prime} \\
& \times \sum_{k=1}^{n} m_{s k}^{\prime} \int_{-\infty}^{\infty} \frac{\exp (-i \omega t)}{-i \omega+\alpha_{j}} F_{k}(\omega) d \omega .
\end{aligned}
$$

Using Fourier integral [39] and changing the order of integration, (41) can be written as

$$
\begin{aligned}
r_{P m}(t) & \\
= & \sum_{j=1}^{2 n} u_{m+n, j} \sum_{s=1}^{n} u_{j s}^{\prime} \sum_{k=1}^{n} m_{s k}^{\prime} \\
& \times \int_{-\infty}^{\infty} F_{k}(\tau)\left[\frac{1}{2 \pi} \int_{-\infty}^{\infty} \frac{\exp [i \omega(\tau-t)]}{-i \omega+\alpha_{j}} d \omega\right] d \tau .
\end{aligned}
$$

Using Cauchy's residue theorem [39], the particular solution can be expressed as

$$
r_{P m}(t)=\sum_{j=1}^{2 n} u_{m+n, j} \sum_{s=1}^{n} u_{j s}^{\prime} \sum_{k=1}^{n} m_{s k}^{\prime} I_{j k},
$$

where

$$
I_{j k}=\int_{0}^{t} \exp \left[\alpha_{j}(\tau-t)\right] F_{k}(\tau) d \tau,
$$

in which $t$ is the bridge loading time. $I_{j k}$ can be split up for convenience as

$$
I_{j k}=I_{j w}+I_{j x}+I_{j y}+I_{j z}
$$

where $w=1,2,3, \ldots, n_{v} ; x=n_{v}+1, n_{v}+2 ; y=n_{v}+3$, $n_{v}+4, \ldots, n_{v}+2+n_{b} ; z=n_{v}+n_{b}+3, n_{v}+n_{b}+4, \ldots, n_{v}+n_{b}+n_{T}+2$.

Closed form expressions for the components of the above integral which generates each of the response samples have been developed and given in the appendix. The response samples thus form complete ensemble of the process. Averaging across the ensemble at each time step yields mean $\mu_{Y}\left(t_{k}\right)$ and standard deviation $\sigma_{Y}\left(t_{k}\right)$ of a response process $Y$.

\section{Results and Discussions}

4.1. Model Validation. The results obtained by present analytical method have been first compared with numerically simulated results and published results from the literature. Newmark integration scheme [40] has been adopted for numerical simulation. Time step for integration purpose has been selected as $0.005 \mathrm{sec}$. Two-axle vehicle model data and bridge of single span with simple supports have been used for comparison purpose. For this purpose, bridge and vehicle parameters have been selected from study conducted by Deng and Cai [41] in which they have also presented experimental

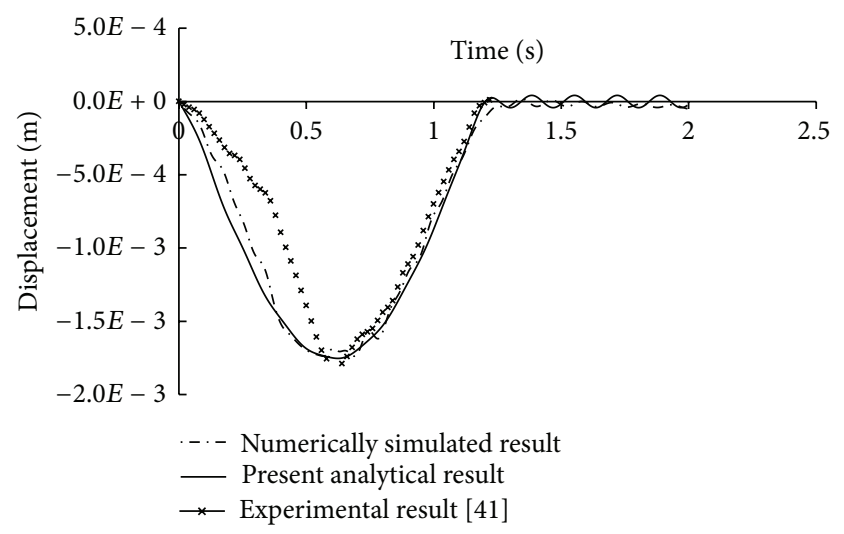

FIGURE 2: Comparison of analytical, numerical, and experimental results.

data. Following are the inputs taken in both analytical model and numerical integration scheme:

span $(L): 16.764 \mathrm{~m}$, mass per unit length $\left(m_{b}\right): 1.08 \times$ $10^{4} \mathrm{~kg} / \mathrm{m}$, flexural rigidity $\left(E_{b} I_{b}\right): 2.48 \times 10^{12} \mathrm{Nm}^{2}$, torsional rigidity $\left(G_{b} J_{b}\right): 2.48 \times 10^{12} \mathrm{Nm}^{2}$, mass moment of inertia $\left(I_{b}\right): 1.87 \times 10^{5} \mathrm{kgm}^{2} / \mathrm{m} ; E_{b}=32 \mathrm{GPa}$, deck = $25.12 \mathrm{GPa}$; vehicle mass $\left(m_{v}\right): 2.48 \times 10^{4} \mathrm{~kg}$, mass of front and rear wheel $\left(m_{w 1}, m_{w 2}\right): 725.4 \mathrm{~kg}$ each, mass moment of inertia $\left(I_{v}\right)$ : $1.72 \times 10^{5} \mathrm{kgm}^{2}$, front and rear suspension stiffness $\left(k_{v 1}, k_{v 2}\right)$ : $7.28 \times 10^{5} \mathrm{~N} / \mathrm{m}, 1.97 \times 10^{6} \mathrm{~N} / \mathrm{m}$, front and rear suspension damping $\left(c_{v 1}, c_{v 2}\right): 2189.6 \mathrm{Ns} / \mathrm{m}, 7181.8 \mathrm{Ns} / \mathrm{m}$, and front and rear tyre stiffness $\left(k_{t 1}, k_{t 2}\right): 1.97 \times 10^{6} \mathrm{~N} / \mathrm{m}, 4.74 \times 10^{6} \mathrm{~N} / \mathrm{m}$. In Figure 2, the analytically obtained response sample has been compared with numerically simulated response sample and experimental results found in [41]. The comparison of response sample exhibits close agreement between analytical and numerically simulated results. The experimental data in the initial portion has shown considerable deviation from theoretical results, which, however, becomes closer in the later part of the response time history. The peak magnitude of the displacement in analytical, numerical, and experimental results agrees well.

4.2. Parametric Study. The following system data have been adopted to generate numerical results and to conduct parametric study: a RC slab-girder bridge of span $(L): 20 \mathrm{~m}$; three longitudinal girders along the span and three crossgirders at midspan and at supports are provided in bridge; the lane width: $8.6 \mathrm{~m}$, deck thickness: $200 \mathrm{~mm}$, and concrete characteristic strength $25 \mathrm{~N} / \mathrm{mm}^{2}$. The cross-section of the bridge is shown in Figure 3. A finite element (FE) model of bridge in SAP2000 commercial software is first developed using the above details of the bridge so as to match the fundamental natural frequency and first modal damping ratio of the simply supported beam model of T-beam bridge. The sectional properties of FE model are then used in the present analytical program of the bridge. The following physical parameters are finally selected for the beam model to represent a T-beam RC concrete bridge:

mass $\left(m_{b}\right): 11.15 \times 10^{3} \mathrm{~kg} / \mathrm{m}$, flexural rigidity $\left(E_{b} I_{b}\right): 3.7 \times$ $10^{10} \mathrm{~N}-\mathrm{m}^{2}$, and torsional rigidity $\left(G_{b} J_{b}\right): 1.695 \times 10^{10} \mathrm{~N}-\mathrm{m}^{2}$. 


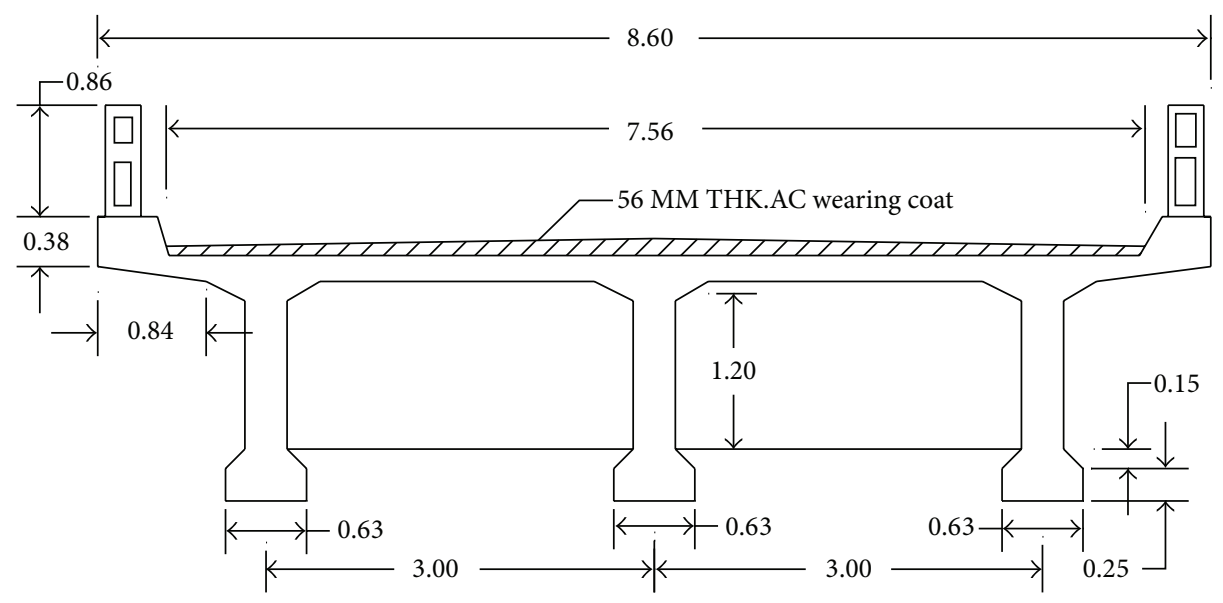

Figure 3: Cross-section of T-beam bridge (all dimensions are in meter).

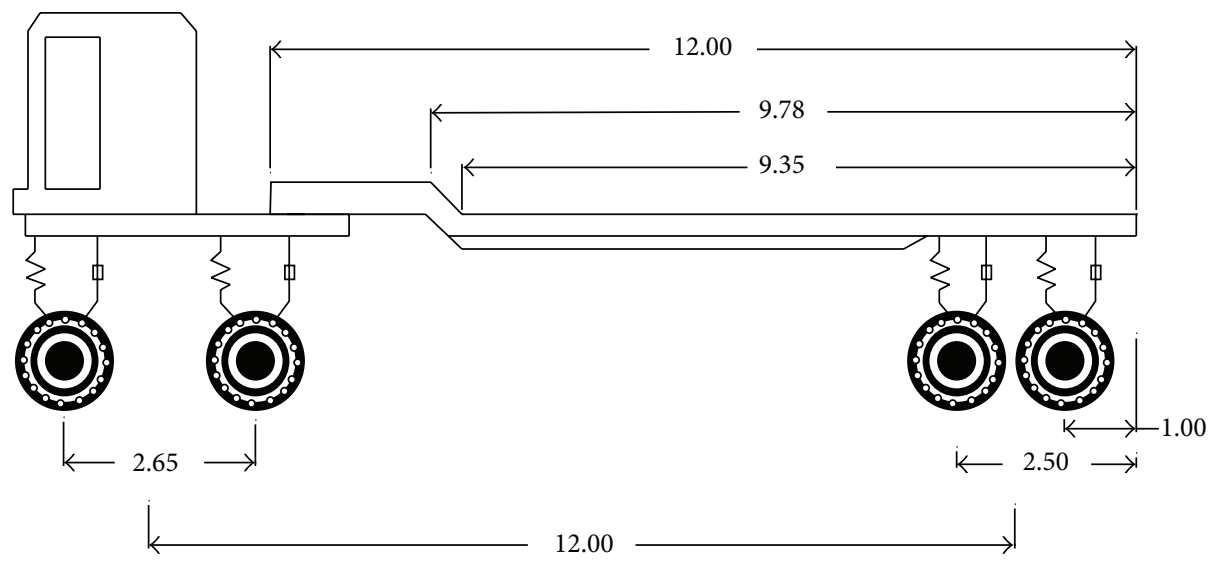

FIgURE 4: Longitudinal section of vehicle (all dimensions are in meter).

The sectional parameters to be given in the beam model of bridge have been found from the FE model of bridge in SAP 2000 commercial software to match the fundamental natural frequency and first modal damping of both the beam and the FE model of bridge.

Vehicle parameters are as follows: a long vehicle carrying heavy load often crossing the bridge has been chosen to illustrate the present approach. The standards of vehicle are different from the live load prescribed by bridge code. In the present study, we use a vehicle type TATA 3516C-EX as shown in Figures 4 and 5. This has been idealized as EulerBernoulli beam adopted in present formulation. Following are the important physical parameters pertaining to vehicle: length $\left(l_{v}\right): 12 \mathrm{~m}$, flexural rigidity $\left(E_{v} I_{v}\right): 5.3 \times 10^{6} \mathrm{~N}-\mathrm{m}^{2}$, mass per unit length $\left(m_{v}\right): 1500 \mathrm{~kg} / \mathrm{m}$, front and rear wheel masses $\left(m_{w 1}, m_{w 2}\right): 800 \mathrm{~kg}$ each, suspension stiffness front and rear $\left(k_{v 1}, k_{v 2}\right): 3.6 \times 10^{7} \mathrm{~N} / \mathrm{m}$, suspension damping front and rear $\left(c_{v 1}, c_{v 2}\right): 7.2 \times 10^{4} \mathrm{~N}-\mathrm{sec} / \mathrm{m}$, front and rear tyre stiffness: $\left(k_{t 1}, k_{t 2}\right): 0.9 \times 10^{7} \mathrm{~N} / \mathrm{m}$, and front and rear tyre damping $\left(k_{t 1}, k_{t 2}\right): 0.7 \times 10^{4} \mathrm{~N}-\mathrm{sec} / \mathrm{m}$.

4.2.1. Bridge Response Statistics. Bridge mean responses at midspan displacement $\left(\mu_{d y}\right)$, velocity $\left(\mu_{v y}\right)$, and acceleration $\left(\mu_{a y}\right)$ subjected to three vehicle speed have been shown in Figures 6,7 , and 8 . The roughness of the bridge deck has been assumed to be of poor category as per ISO classification corresponding to roughness coefficient $\varsigma_{s}=16 \times$ $10^{-6} \mathrm{~m}^{2} /(\mathrm{m} /$ cycle $)$ [42]. The mean peak central deflection is found to increase with the vehicle speed. The corresponding standard deviation of each response displacement $\left(\sigma_{d z}\right)$, velocity $\left(\sigma_{v z}\right)$, and acceleration $\left(\sigma_{a z}\right)$ has been shown in Figures 9,10 , and 11. It may be noted that bridge response frequency is modified by change in vehicle velocity and obtained behavior has appropriate physical sense that higher velocity increases the temporal frequency of road excitation. This is obvious from left shift of the peak when velocity increases from lower to higher. The peak magnitude is also higher in case of vehicle travelling with higher velocity. No definite pattern is discernible in the standard deviation. Although, the magnitudes of standard deviation are insignificant for practical purpose, magnitudes of the coefficient of variation of peak displacement, velocity, and accelerations are found to be $0.11,0.183$, and 0.105 , respectively. It may be mentioned that dynamic loads do not lead to major bridge damage, except in resonance, but they contribute to continuous degradation of bridge increasing necessity of bridge maintenance. 

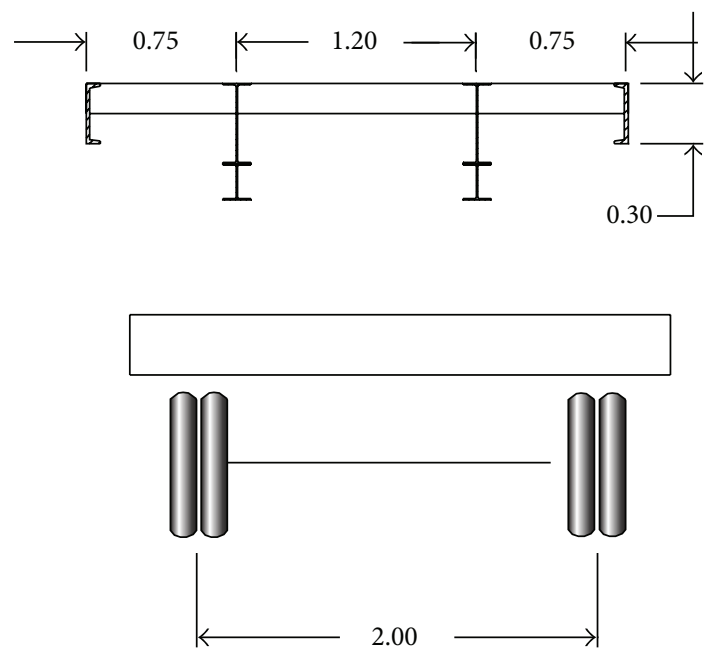

Figure 5: Vehicle cross-section (all dimensions are in meter).

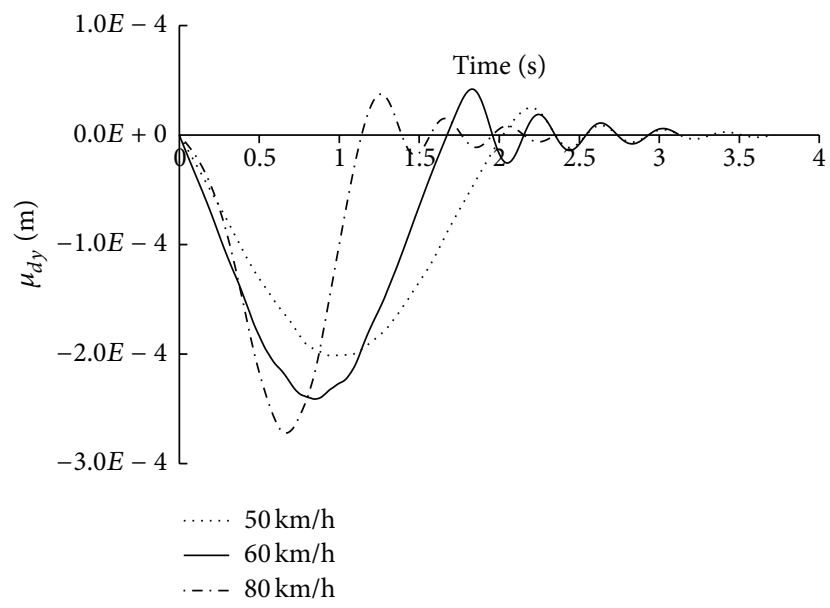

FIgURE 6: Mean displacement of bridge at the midspan.

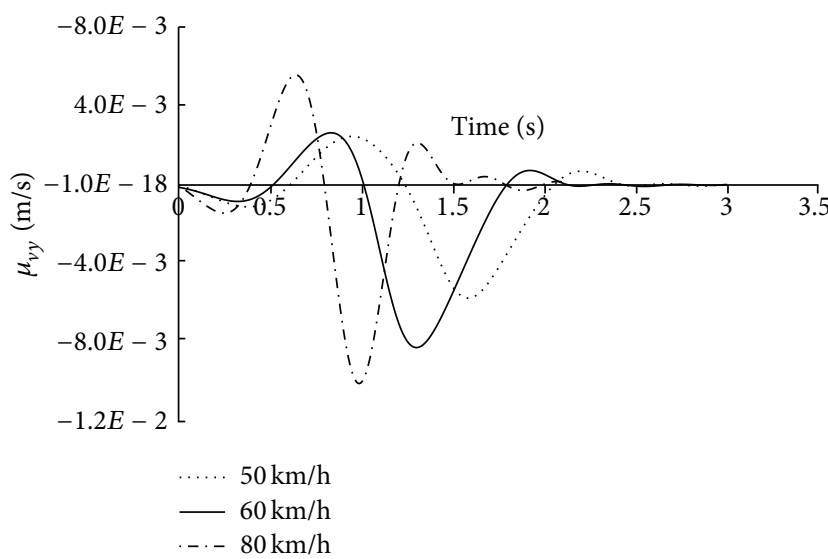

FIgURE 7: Mean velocity of bridge at the midspan.

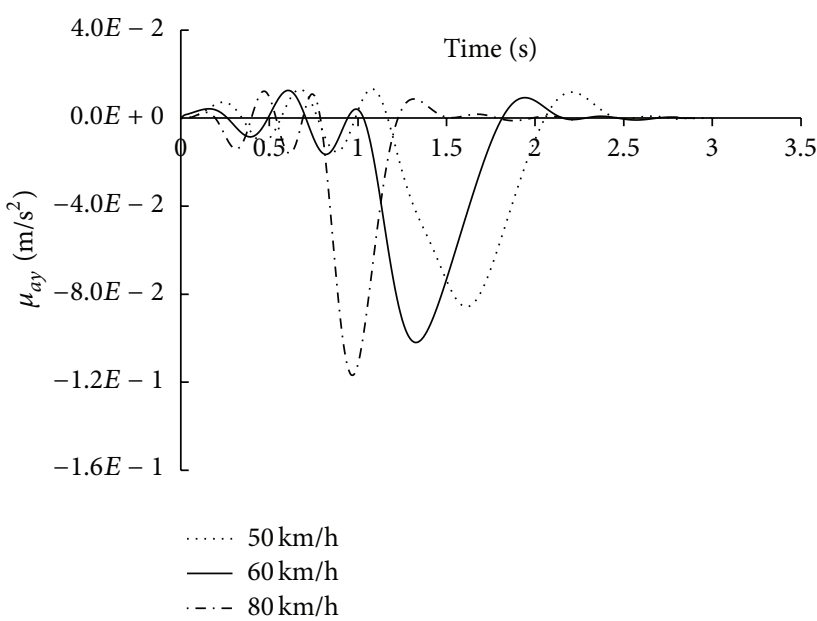

FIGURE 8: Mean acceleration of bridge at the midspan.

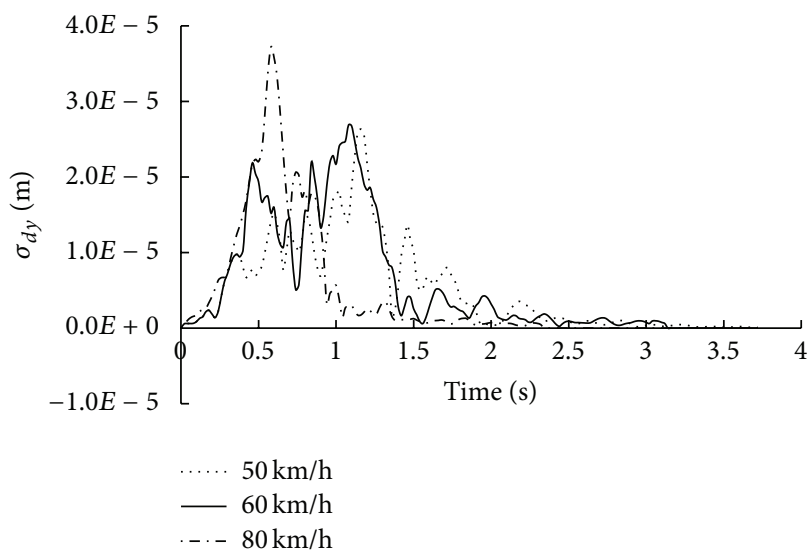

FIgURE 9: Standard deviation of bridge midspan deflection.

4.2.2. Vehicle Response Statistics. The mean vehicle body responses (at centroid) - displacement $\left(\mu_{d z}\right)$, velocity $\left(\mu_{v z}\right)$, and acceleration $\left(\mu_{a z}\right)$ time history-including residual response have been shown in Figures 12, 13, and 14. The corresponding standard deviation of responses displacement $\left(\sigma_{d z}\right)$, velocity $\left(\sigma_{v z}\right)$, and acceleration $\left(\sigma_{a z}\right)$ is shown in Figures 15,16 , and 17. It has been seen that the peak response is increased with increase in vehicle speed. Standard deviation has no definite trend in the present case for vehicle response.

4.2.3. Effect of Vehicle Flexibility on Mean and Standard Deviation. The contribution of significant number of structural modes of vehicle to bridge response has been examined in a bar diagram presented in Figures 18 and 19 by comparing maximum mean and standard deviation, respectively. It may be seen that inclusion of bending modes of the vehicle reduces the response magnitude of the bridge. The same figure also reveals that when flexible modes of the vehicle are considered, summation of first five modes for finding the response is adequate. Figures 20 and 21 show the comparison of mean 


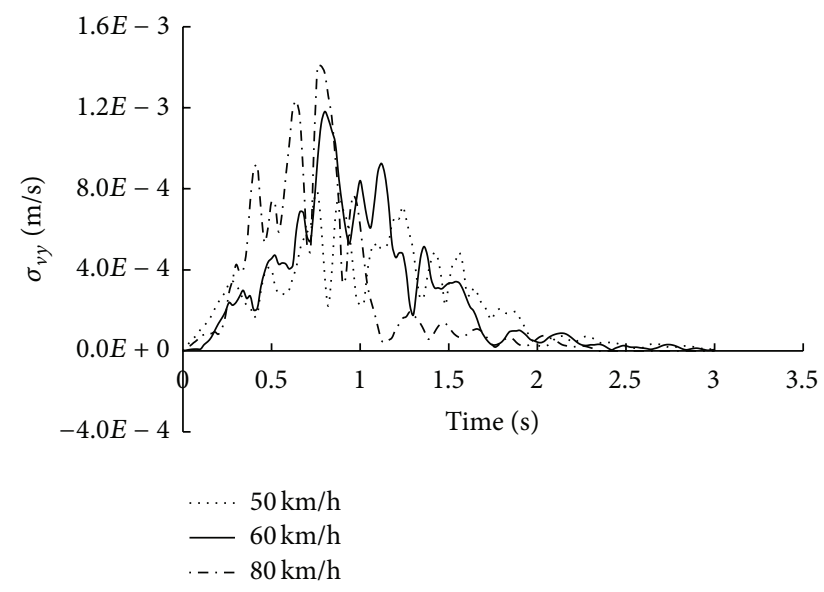

FIGURE 10: Standard deviation of bridge midspan velocity.

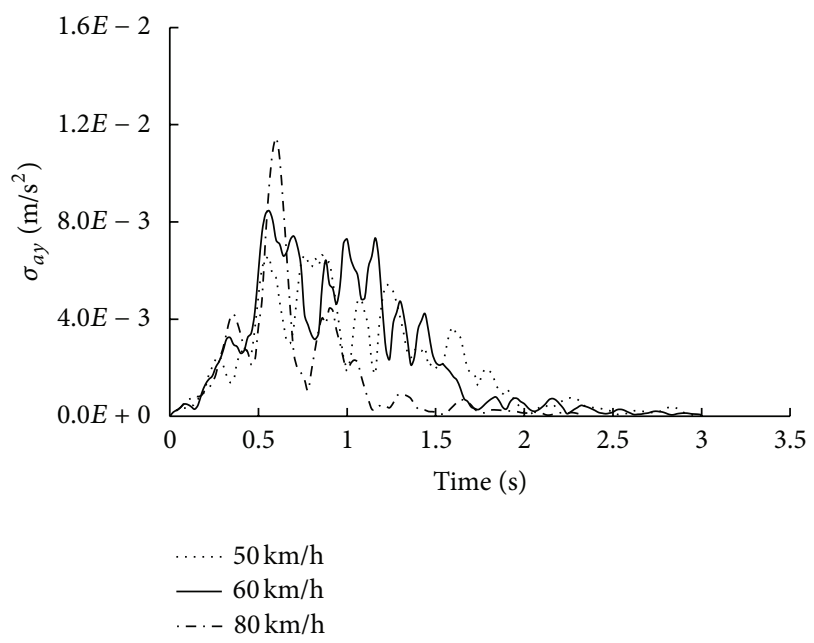

FIGURE 11: Standard deviation of bridge midspan acceleration.

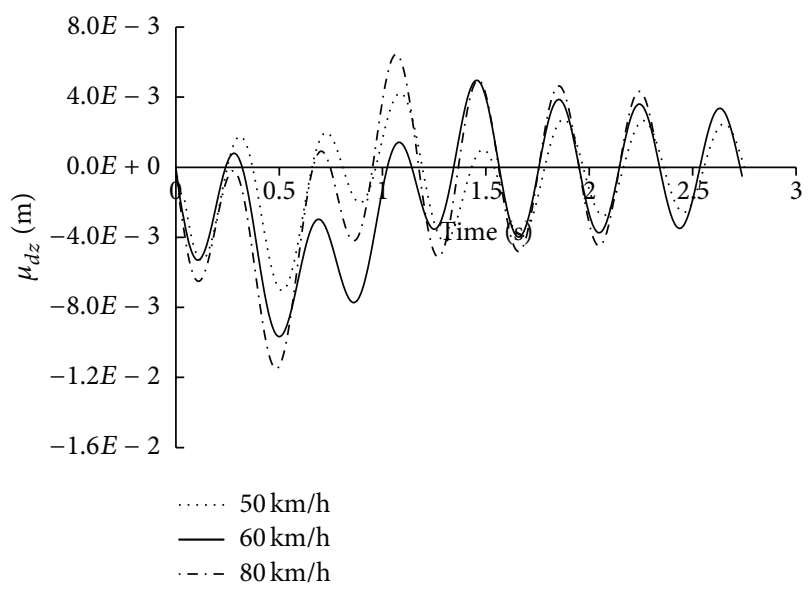

FIgURE 12: Mean displacement of vehicle C.G.

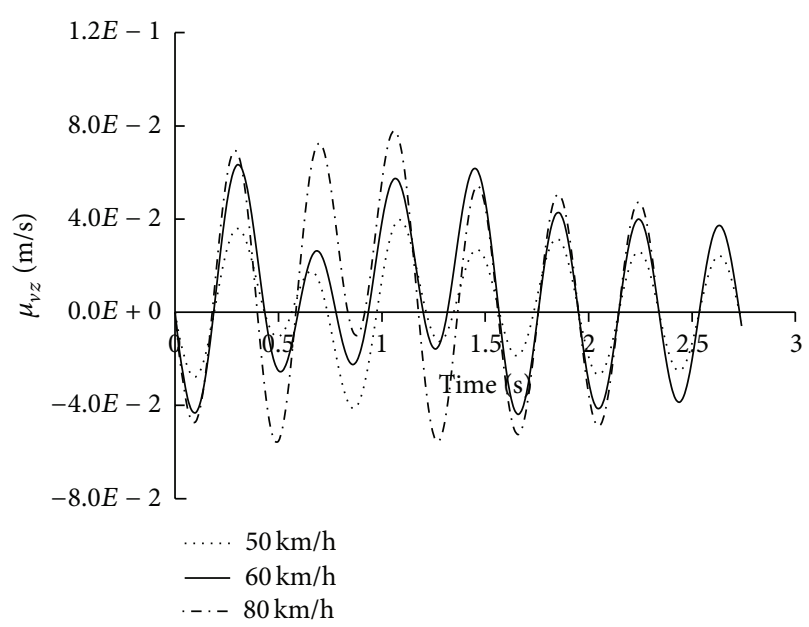

FIGURE 13: Mean velocity of vehicle at C.G.

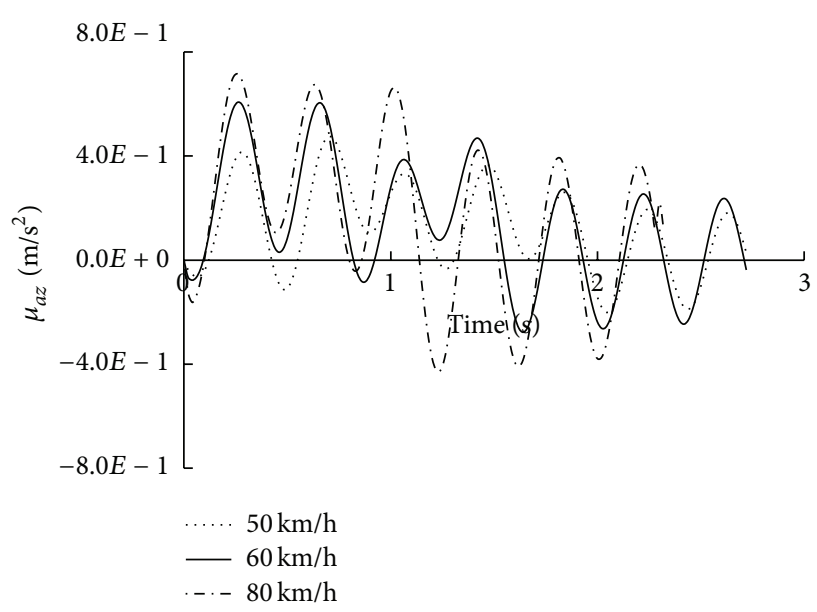

FIgURE 14: Mean acceleration of vehicle at C.G.

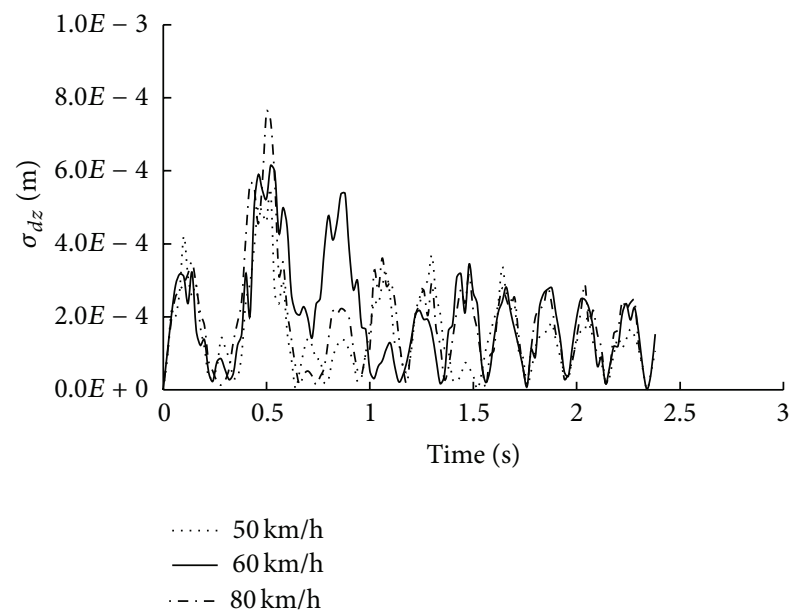

FIGURE 15: Standard deviation of vehicle displacement at C.G. 

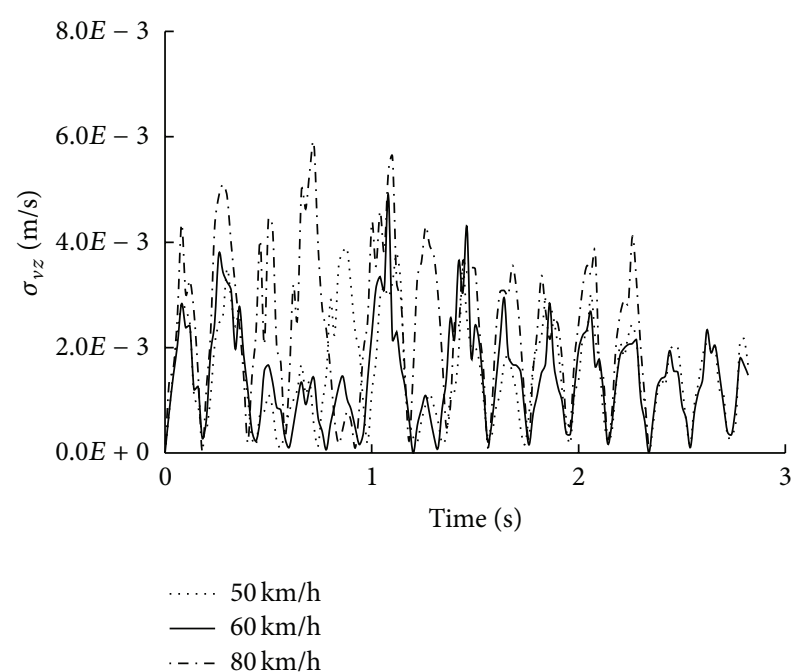

FIGURE 16: Standard deviation of vehicle velocity at C.G.
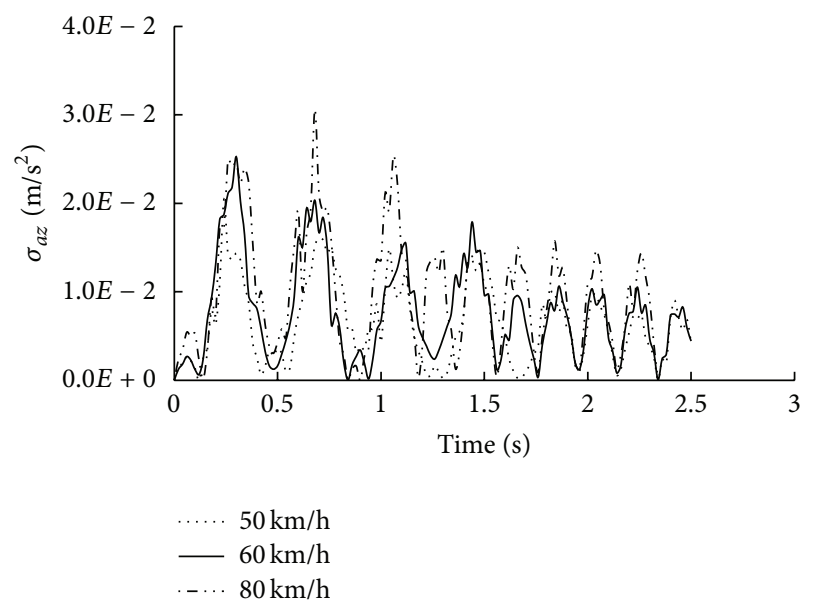

FIGURE 17: Standard deviation of vehicle acceleration at C.G.

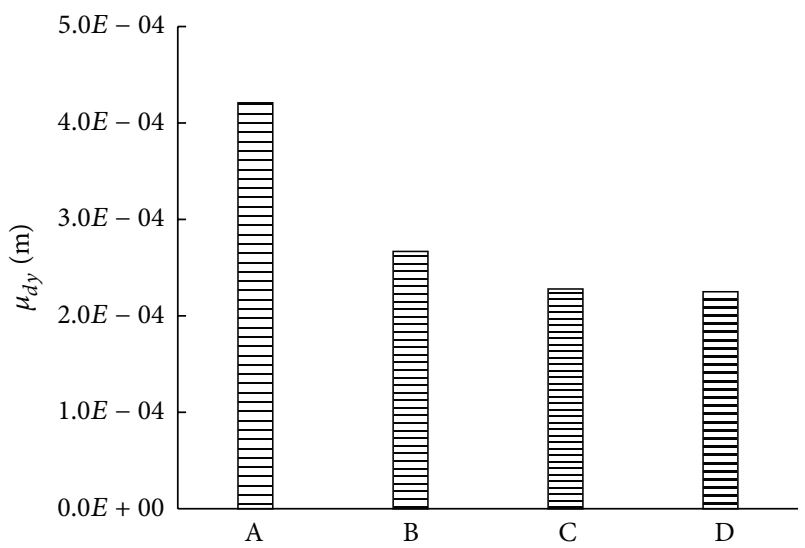

FIGURE 18: Maximum mean displacement of bridge at midspan, (A) rigid vehicle, (B) flexible vehicle only with first structural mode, (C) flexible vehicle with first three structural modes, and (D) flexible vehicle with first five structural modes.

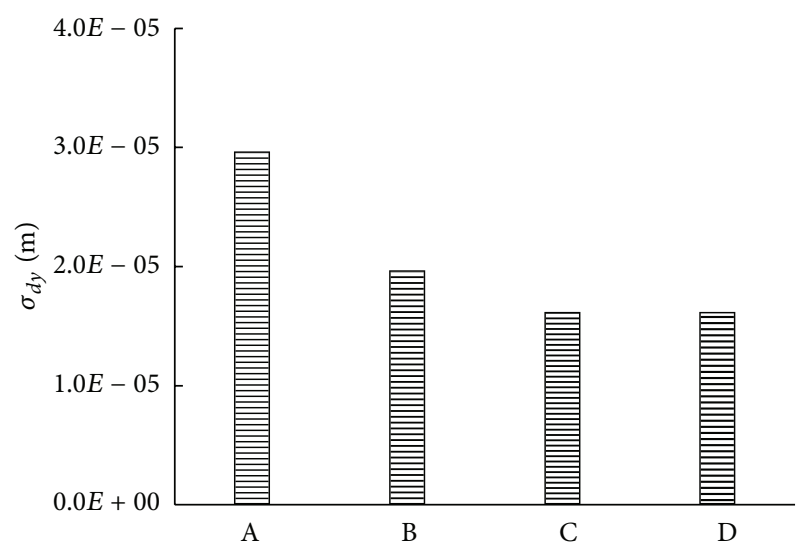

FIgURE 19: Maximum standard deviation of displacement at midspan, (A) rigid vehicle, (B) flexible vehicle only with first structural mode, (C) flexible vehicle with first three structural modes, and (D) flexible vehicle with first five structural modes.
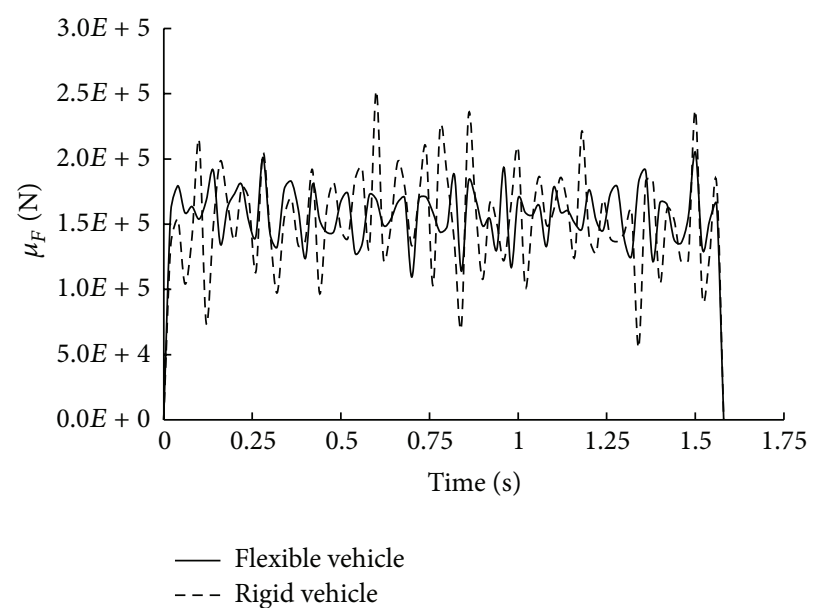

FIGURE 20: Mean of imposed force time history of the bridge due to passage of rigid and flexible vehicle.

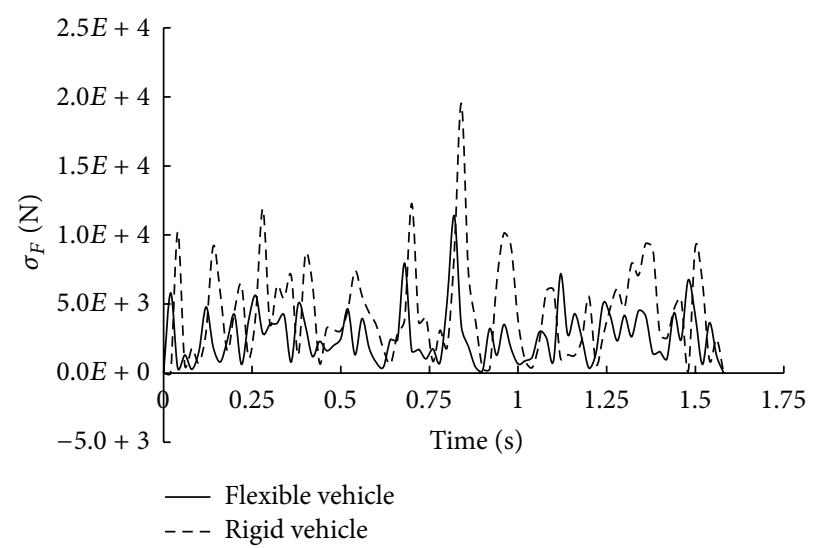

FIGURE 21: Standard deviation of imposed force time history of the bridge due to passage of rigid and flexible vehicle. 


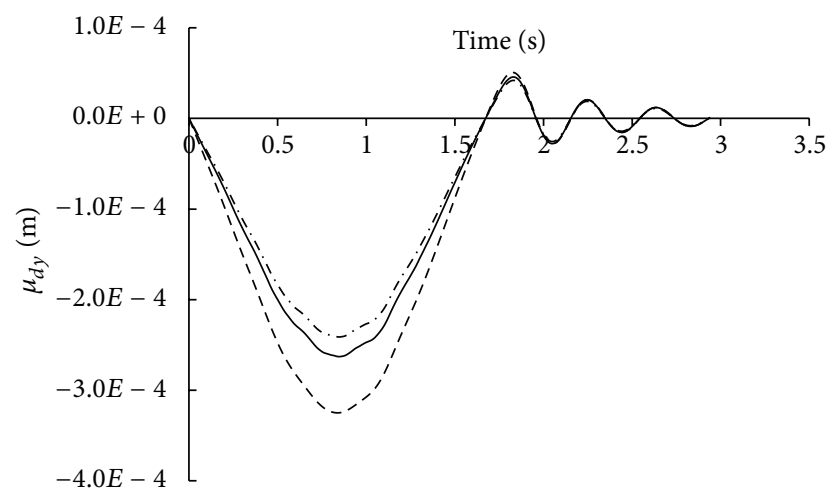

$$
\begin{array}{r}
\ldots \mathrm{A} \\
-\mathrm{B} \\
\ldots \mathrm{C}
\end{array}
$$

FIGURE 22: Effect of flexibility on mean response of bridge, (A) $E_{v} I_{v}=5.3 \times 10^{6} \mathrm{~N}-\mathrm{m}^{2}$, (B) $E_{v} I_{v}=6.4 \times 10^{7} \mathrm{~N}-\mathrm{m}^{2}$, and (C) $E_{v} I_{v}=$ $8.2 \times 10^{10} \mathrm{~N}-\mathrm{m}^{2}$.

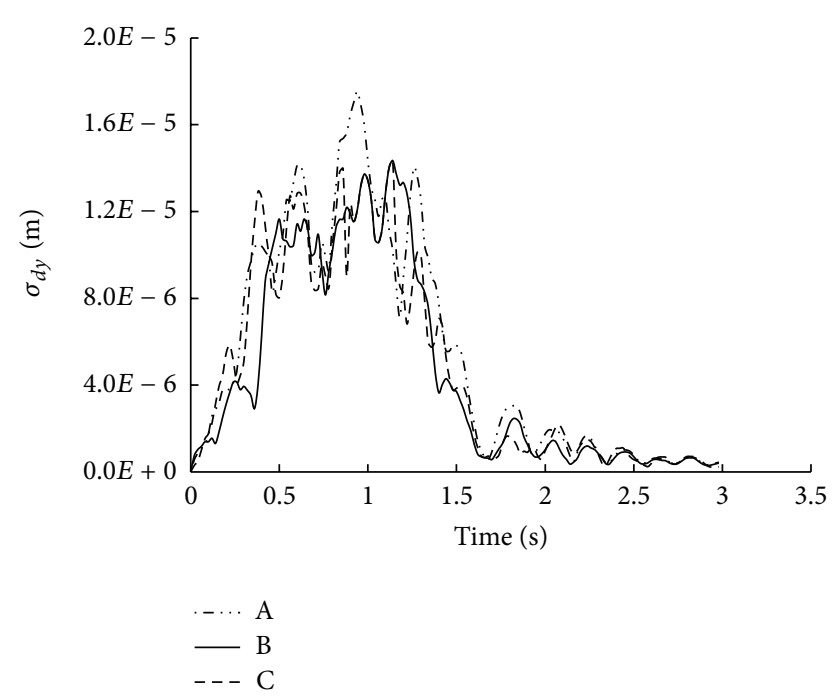

FIGURE 23: Effect of flexibility on standard deviation of bridge response, (A) $E_{v} I_{v}=5.3 \times 10^{6} \mathrm{~N}-\mathrm{m}^{2}$, (B) $E_{v} I_{v}=6.4 \times 10^{7} \mathrm{~N}-\mathrm{m}^{2}$, and (C) $E_{v} I_{v}=8.2 \times 10^{10} \mathrm{~N}-\mathrm{m}^{2}$.

and standard deviation of imposed force on the bridge due to passage of a rigid vehicle with those of flexible vehicle. It reveals that when structural bending modes are considered, the imposed force on the bridge is less. This may be attributed to the fact that part total strain energy has been utilized in bending of elastic vehicle body as compared to rigid beam, which reduces imposed force on the bridge.

The comparison of mean response of bridge at midspan with different values of vehicle flexural rigidity has been presented in Figure 22. Corresponding standard deviation is presented in Figure 23. It may be noted that vehicle with lower flexural rigidity generates less response in the bridge. In generating numerical results under this section vehicle velocity is taken as $60 \mathrm{~km} / \mathrm{h}$.

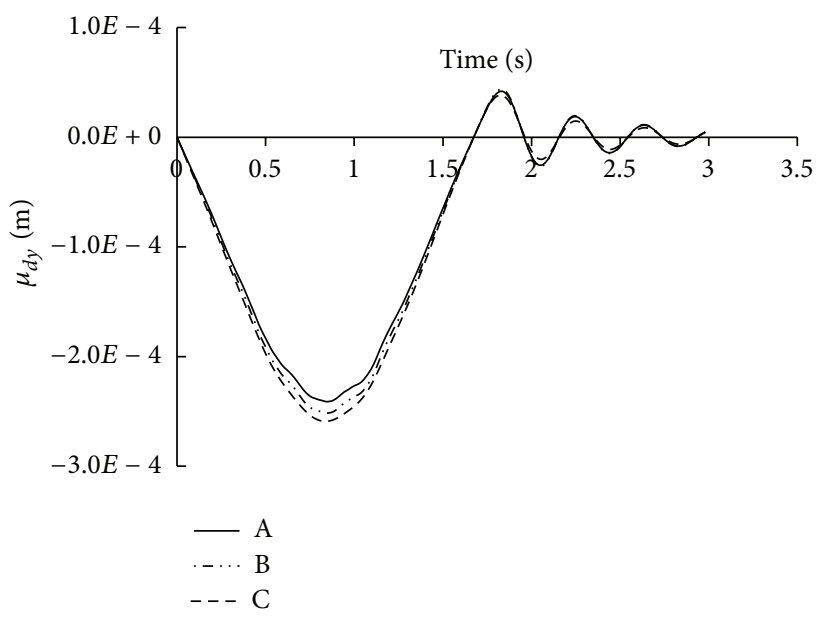

FIgURE 24: Mean of bridge midspan displacement due to different eccentricity of vehicle path $\left(e_{x}\right),(\mathrm{A}) e_{x}=0.5 \mathrm{~m},(\mathrm{~B}) e_{x}=1 \mathrm{~m}$, and (C) $e_{x}=1.5 \mathrm{~m}$.

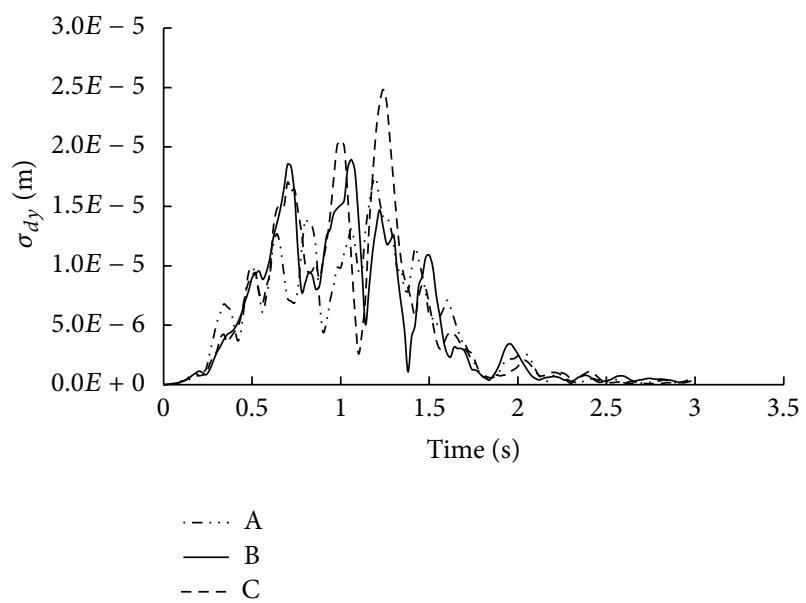

FIGURE 25: Standard deviation of bridge midspan displacement due to different eccentricity of vehicle path $\left(e_{x}\right),(\mathrm{A}) e_{x}=0.5 \mathrm{~m},(\mathrm{~B}) e_{x}=$ $1 \mathrm{~m}$, and $(\mathrm{C}) e_{x}=1.5 \mathrm{~m}$.

4.2.4. Effect of Eccentricity of Vehicle Path on Mean and Standard Deviation. The effect of eccentricity on the bridge response has been studied by varying the loading position from the centre of the bridge width. In the result shown in Figures 24 and 25, 6\% to $8 \%$ increment in the bridge dynamic responses has been observed as the eccentricity varies from $0.5 \mathrm{~m}$ to $1.5 \mathrm{~m}$. The vehicle stiffness for comparing the results in Figures 24 and 25 is taken uniform $\left(E_{v} I_{v}=5.3 \times 10^{6} \mathrm{~N} \cdot \mathrm{m}^{2}\right)$. In generating numerical results under this section vehicle velocity is taken as $60 \mathrm{~km} / \mathrm{h}$.

4.3. Dynamic Amplification Factor (DAF). Considering any response variable $Y$ as random process, the maximum dynamic response can be written as

$$
Y_{\text {dynamic }}=\left|\mu_{Y}\left(x_{k}, t_{k}\right)+\sigma_{Y}\left(x_{k}, t_{k}\right)\right| \text {, }
$$




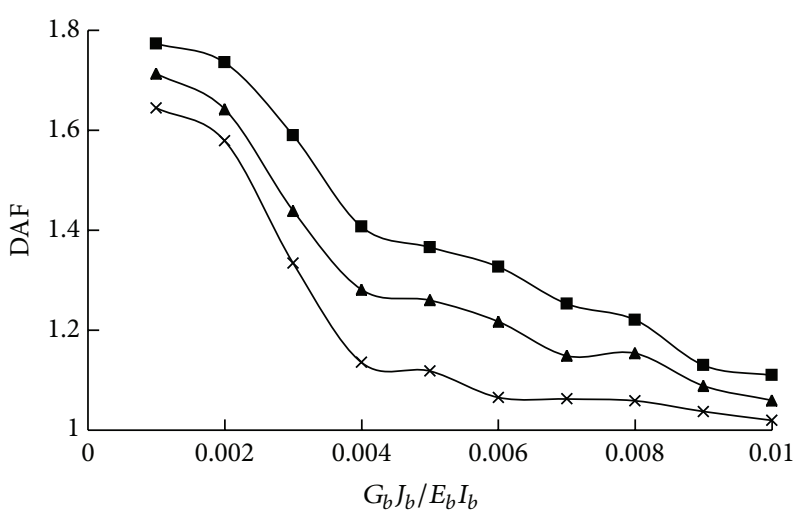

$* \mathrm{~A}$
$\leftarrow \mathrm{B}$
$\rightarrow-\mathrm{C}$

FIGURE 26: Dynamic amplification factor (DAF) with the ratio of bridge torsional rigidity to flexural rigidity $\left(G_{b} J_{b} / E_{b} I_{b}\right)$ for different vehicle flexural rigidity. (A) $E_{v} I_{v}=5.3 \times 10^{6} \mathrm{~N}-\mathrm{m}^{2}$, (B) $E_{v} I_{v}=6.4 \times$ $10^{7} \mathrm{~N}-\mathrm{m}^{2}$, and (C) $E_{v} I_{v}=8.2 \times 10^{10} \mathrm{~N}-\mathrm{m}^{2}$.

where $Y_{\text {dynamic }}$ denotes the maximum response due to fluctuating load imposed on bridge due to vibratory motion of the vehicle excited by road unevenness.

Thus, dynamic amplification factor (DAF) in this study is defined as

$$
\mathrm{DAF}=\frac{Y_{\text {static }}+Y_{\text {dynamic }}}{Y_{\text {static }}},
$$

where $Y_{\text {static }}$ refers to the response of the bridge at the midspan location for adverse position of static wheel loads.

4.3.1. Effect of Bridge Torsional Rigidity on Dynamic Amplification Factor (DAF). The effect of torsional rigidity of bridge has been studied by obtaining DAF for different ratios of torsional rigidity $\left(G_{b} J_{b}\right)$ to flexural rigidity $\left(E_{b} I_{b}\right)$ of bridge with various values of vehicle flexural rigidity $\left(E_{v} I_{v}\right)$ and presented in Figure 26. The results reveal that dynamic amplification factor decreases by an amount of $23 \%$ to $34 \%$ when the ratio of torsional rigidity to flexural rigidity of bridge increases from 0.002 to 0.01 . This indicates that torsionally stiffer bridge produces less dynamic amplification of static live load response.

4.3.2. Effect of Vehicle Mass and Speed on DAF. Since dynamic amplification factor depends on several variables, we choose to represent it by surface plot rather than a two-dimensional plot. The effect of vehicle mass as well as speed on the dynamic amplification factor (DAF) has been shown in Figure 27. Individual effect on earlier classical studies [43] has shown that effect of increasing mass has reducing effect on DAF. However, a surface plot shown in Figure 18 shows that combined effect has an increasing trend. Earlier authors argued that reduction of dynamic amplification factor with increasing vehicle weight is due to increase of static deflection. However, the coupled dynamic interaction may be the cause of increased inertia force in addition to suspension force imposed by moving mass at greater velocity, which increases dynamic component of the response.

4.3.3. Effect of Bridge Surface Roughness and Speed. The surface roughness and speed of the vehicle are two most influential factors that can cause increased dynamic amplification factor and rapid degradation of the bridge. Bridge dynamic amplification factor has been found by changing bridge surface roughness coefficient for good condition to poor condition as mentioned in ISO specification [42] with change in vehicle speed. Figure 28 shows that poor condition of road induces more deflection on the bridge when vehicle moves over it and also can be catalyzed by vehicle speed.

4.3.4. Effect of Bridge Span and Velocity. The span of the bridge is an important factor which decides the impact factor in most of the bridge design codes. Combined effect of bridge span and speed of the vehicle on DAF is not fully known. Figure 29 shows the DAF with variation of bridge span and velocity. It has been found that when the bridge span increases from $14 \mathrm{~m}$ to $30 \mathrm{~m}$ dynamic amplification factor decreases by an amount of $12 \%$ to $15 \%$, irrespective of increase of vehicle velocity. Although increasing span shows a decreasing trend in DAF similar to the earlier studies, the increment found in the present case is not very significant for the range of span 14-30 m

\section{Conclusions}

In the present study, an analytical solution for coupled vehicle-bridge interaction problem considering eccentrically moving flexible vehicle as well as random deck surface roughness has been obtained. Response samples are generated from the expressions derived in the present study considering nonhomogeneity of deck roughness. The results obtained from analytical approach have been validated with numerical simulation and experimental data available in the literature. Individual and combined effects of several bridge-vehicle parameters have been considered to find out the response statistics. The increased effect of vehicle speed has been found more significant in changing the frequency of imposed oscillation rather than noticeable increase in response peaks. Combined effect of increasing vehicle weight and speed has been found to increase the dynamic amplification factor. The study reveals that flexibility of long vehicle is an important consideration in obtaining bridge response and, due to change in load carrying vehicle configuration, it is now imperative to address this issue in bridge design codes. Torsion of the bridge is activated by eccentric movement of vehicle, and dynamic amplification factor is largely dependent on the ratio of torsional rigidity to flexural rigidity of bridge cross-section. 


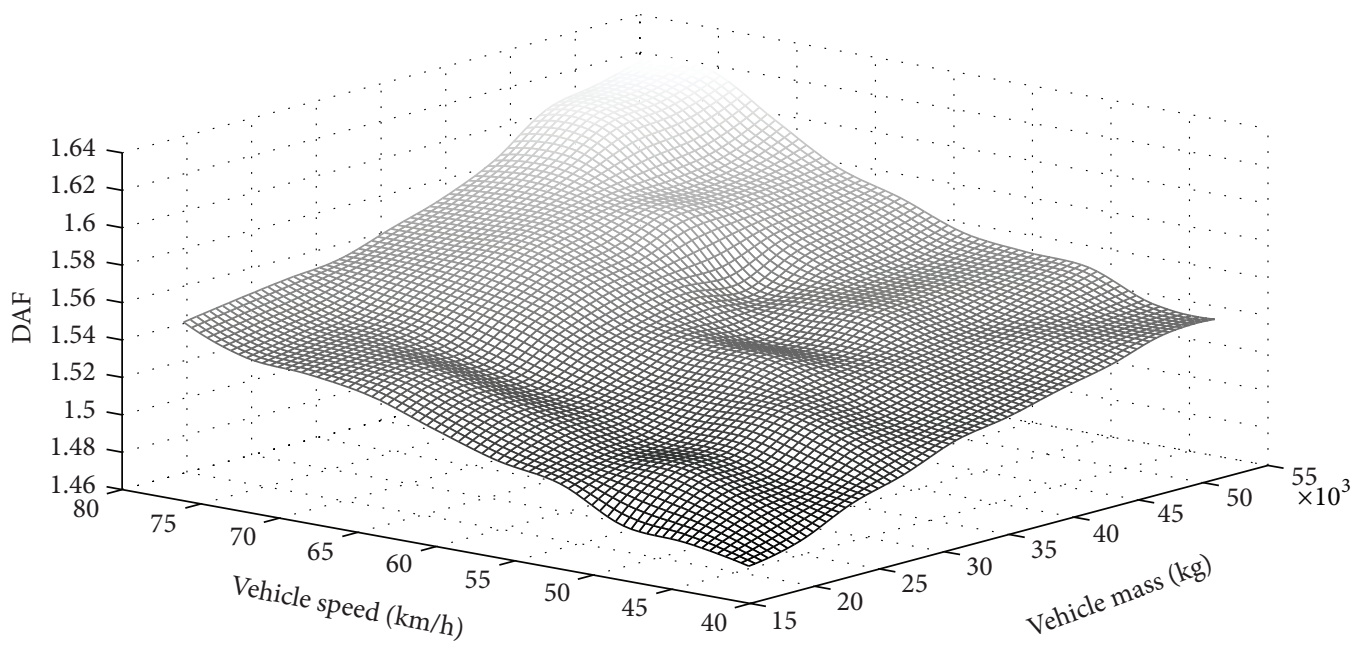

FIGURE 27: Dynamic amplification factor with change in vehicle speed and vehicle mass.

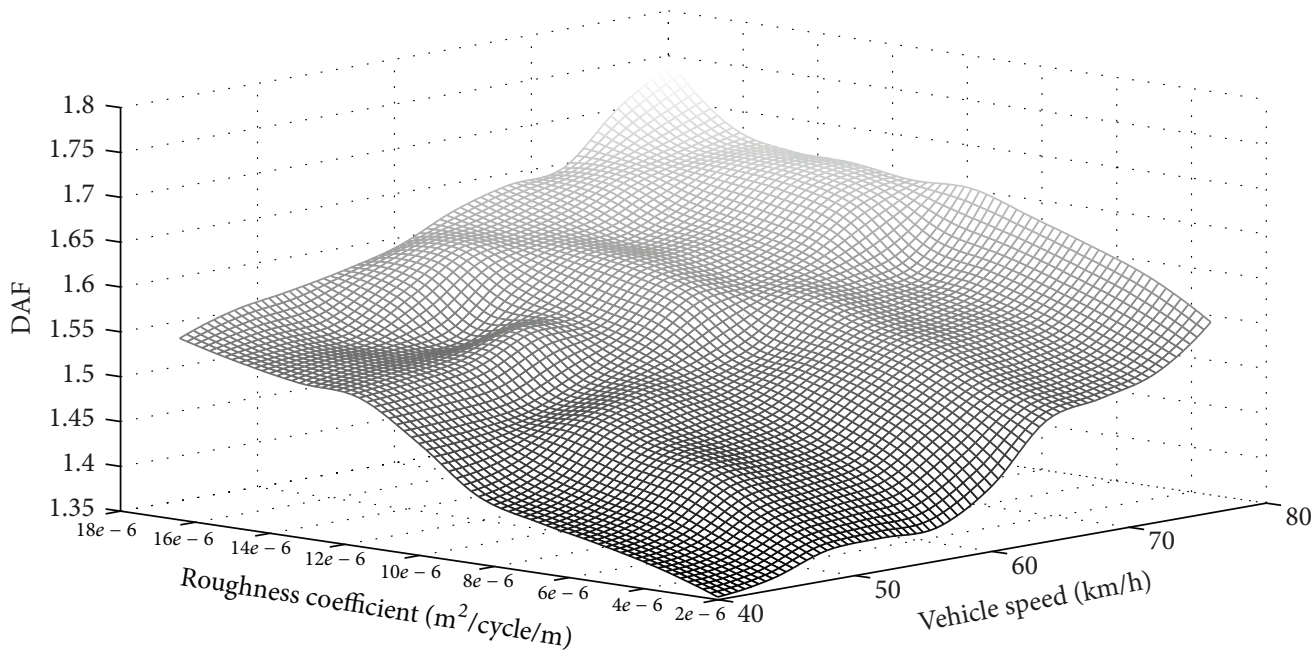

FIGURE 28: Dynamic amplification factor with vehicle speed and bridge surface roughness.

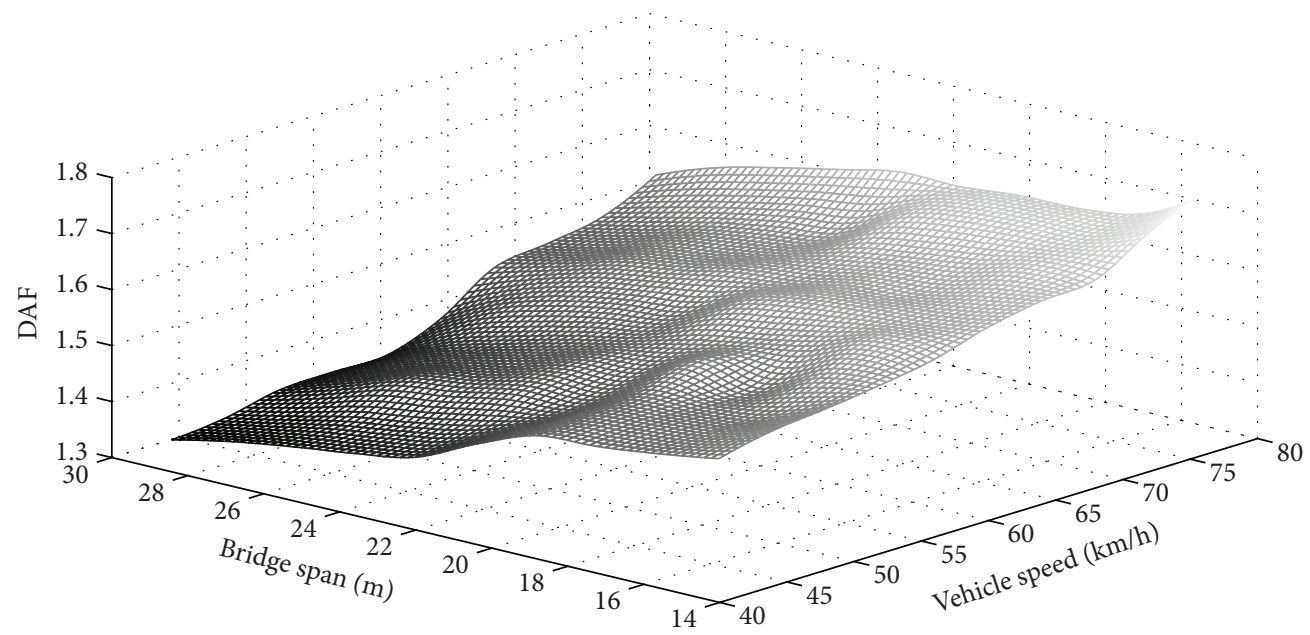

FIGURE 29: Dynamic amplification factor with change in bridge span and vehicle speed. 


\section{Appendix}

\section{Expression of the Integral $I_{j k}$ for \\ Generating Response Sample}

The vector $\{F(t)\}$ needed to perform the integration is given below:

$$
\begin{array}{r}
F_{j}(t)=0 \quad \text { for } j=1,2,3, \ldots, n_{v} \\
=k_{t j-n_{v}} h\left(x_{j-n_{v}}\right)+c_{t j-n_{v}} \dot{h}\left(x_{j-n_{v}}\right) \\
\text { For } j=n_{v}+1, n_{v}+2 \\
=k_{t 1} h\left(x_{1}\right) \phi_{b j-(n v+2)}\left(x_{1}\right)+k_{t 2} h\left(x_{2}\right) \\
+c_{t 1} \dot{h}\left(x_{1}\right) \phi_{b j-(n v+2)}\left(x_{1}\right)+c_{t 2} \dot{h}\left(x_{2}\right) \\
\quad \text { For } j=n_{v}+3, n_{v}+ \\
=e_{x}\left\{k_{t 1} h\left(x_{1}\right) \phi_{t j-\left(n_{v}+2+n_{b}\right)}\left(x_{1}\right)\right. \\
\quad+k_{t 2} h\left(x_{2}\right) \phi_{t j-\left(n_{v}+2+n_{b}\right)}\left(x_{2}\right) \\
+c_{t 1} \dot{h}\left(x_{1}\right) \phi_{t j-\left(n_{v}+2+n_{b}\right)}\left(x_{1}\right) \\
\left.+c_{t 2} \dot{h}^{\prime}\left(x_{2}\right) \phi_{t j-\left(n_{v}+2+n_{b}\right)}\left(x_{2}\right)\right\} \\
\quad \text { For } j=n_{v}+n_{b}+3, \\
n_{v}+n_{b}+4, \ldots, n_{v}+n_{b}+n_{t}+2 .
\end{array}
$$$$
=k_{t 1} h\left(x_{1}\right) \phi_{b j-(n v+2)}\left(x_{1}\right)+k_{t 2} h\left(x_{2}\right) \phi_{b j-(n v+2)}\left(x_{2}\right)
$$$$
+c_{t 1} \dot{h}\left(x_{1}\right) \phi_{b j-(n v+2)}\left(x_{1}\right)+c_{t 2} \dot{h}\left(x_{2}\right) \phi_{b j-(n v+2)}\left(x_{2}\right)
$$$$
\text { For } j=n_{v}+3, n_{v}+4, \ldots, n_{v}+2+n_{b}
$$

The mean surface profile has been taken as shallow parabolic, the equation of which with respect to one end of the bridge is given by

$$
h_{m}(x)=\frac{4 h_{0}}{L^{2}} x(L-x) .
$$

For one trial, a generation of a set of random phase angles $\theta_{s}$ $(s=1,2, \ldots, N)$ is employed to express a Gaussian process is

$$
h_{r}(x)=\sum_{s=1}^{N} A_{s} \cos \left(2 \pi \Omega_{s} x+\theta_{s}\right) \text {. }
$$

Further $h^{\prime}(x)=d h / d x$ and $\dot{h}(x)=d h / d t=V(d h / d x)$ where $V$ is the speed of vehicle.

For convenience of computation,

$$
I_{j k}=I_{j w}+I_{j x}+I_{j y}+I_{j z}
$$

where $w=1,2,3, \ldots, n_{v} ; x=n_{v}+1, n_{v}+2 ; y=n_{v}+2+1$, $n_{v}+2+2, \ldots, n_{v}+2+n_{b} ; z=n_{v}+2+n_{b}+1, n_{v}+2+n_{b}+$ $2, \ldots, n_{v}+2+n_{b}+n_{T}$. as

The first term $I_{j w}\left(w=1,2, \ldots, n_{v}\right)$ of (A.4) can be written

$$
I_{j 1}=I_{j 2}=\cdots=I_{j n_{v}}=0 .
$$

The second term of (A.4) can be written as

$$
I_{j x}=I_{j x 1}+I_{j x 2} .
$$

Splitting the first term of integral (A.6) again into two, we get

$$
I_{j x 1}=I_{j x 11}+I_{j x 12} .
$$

Introducing $A_{s}=\sqrt{2 S\left(V \Omega_{s}\right)^{-2}}$ and $B_{s}=2 \pi\left\{\Omega_{L}+(s-\right.$ $\left.0.5)\left(\Omega_{U}-\Omega_{L}\right) / N\right\}$, the components can be written as

$I_{j \times 11}$

$$
\begin{aligned}
& =k_{t 1}\left[\sum _ { s = 1 } ^ { N } A _ { s } \frac { \operatorname { e x p } ( - \alpha _ { j } t ) } { \alpha _ { j } ^ { 2 } + ( B _ { s } V ) ^ { 2 } } \left\{-\alpha_{j} \cos \left(\theta_{s}\right)-B_{s} V \sin \left(\theta_{s}\right)\right.\right. \\
& +\exp \left(\alpha_{j} t\right) \\
& \times\left[\alpha_{j} \cos \left(B_{s} V t+\theta_{s}\right)\right. \\
& \left.\left.+B_{s} V \cos \left(B_{s} V t+\theta_{s}\right)\right]\right\} \\
& +\frac{4 h_{0} V}{\alpha_{j}^{3} L^{2}}\left\{\alpha_{j} L\left(\alpha_{j} t+\exp \left(-\alpha_{j} t\right)-1\right)\right\} \\
& \left.-\frac{V}{\alpha_{j}^{3} L^{2}}\left\{\alpha_{j} t\left(\alpha_{j} t-2\right)-2 \exp \left(-\alpha_{j} t\right)+2\right\}\right],
\end{aligned}
$$

$I_{j x 12}$

$$
\begin{aligned}
=c_{t 1}\left[\sum_{s=1}^{N} V A_{s} B_{s} \frac{\exp \left(-\alpha_{j} t\right)}{\alpha_{j}^{2}+\left(B_{s} V\right)^{2}}\{\right. & \alpha_{j} \sin \left(\theta_{s}\right)-B_{s} V \cos \left(\theta_{s}\right) \\
+ & \exp \left(\alpha_{j} t\right) \\
\times & {\left[\alpha_{j} \sin \left(B_{s} V t+\theta_{s}\right)\right.} \\
& \left.\left.-B_{s} V \sin \left(B_{s} V t+\theta_{s}\right)\right]\right\}
\end{aligned}
$$

$$
\begin{aligned}
& -\frac{4 h_{0} V \exp \left(-\alpha_{j} t\right)}{\alpha_{j}^{3} L^{2}} \\
& \times\left\{2 V\left[\exp \left(-\alpha_{j} t\right)\left(\alpha_{j} t-1\right)+1\right]\right\} \\
& \left.-\frac{1}{\alpha_{j} L}\left\{\exp \left(\alpha_{j} t\right)-2\right\}\right] .
\end{aligned}
$$


Similarly, splitting the second term of integral (A.6) into two, we get

$$
I_{j x 2}=I_{j x 21}+I_{j x 22}
$$

$I_{j \times 21}$

$$
\begin{gathered}
=k_{t 2}\left[\sum_{s=1}^{N} A_{s} \frac{\exp \left(-\alpha_{j} t\right)}{\alpha_{j}^{2}+\left(B_{s} V\right)^{2}}\right. \\
\times\left\{-\alpha_{j} \cos \left(B_{s} l_{v}-\theta_{s}\right)-B_{s} V \sin \left(B_{s} l_{v}-\theta_{s}\right)\right. \\
+\exp \left(\alpha_{j} t\right)\left[\alpha_{j} \cos \left(B_{s}(l-V t)-\theta_{s}\right)\right. \\
\left.+B_{s} V \sin \left(B_{s}\left(l_{v}-V t\right)+\theta_{s}\right)\right] \\
+\frac{4 h_{0}}{\alpha_{j}^{3} L^{2}}\left\{-\alpha_{j}^{2} l_{v}\left(l_{v}+L\right)\left(\exp \left(\alpha_{j} t\right)-1\right)\right. \\
\left.\left.+\alpha_{j} V\left(2 l_{v}+L\right)\left[\exp \left(\alpha_{j} t\right)\left(\alpha_{j} t-1\right)+1\right]\right\}\right],
\end{gathered}
$$

$I_{j \times 22}$

$$
=c_{t 2}\left[\sum _ { s = 1 } ^ { N } A _ { s } B _ { s } V \frac { \operatorname { e x p } ( - \alpha _ { j } t ) } { \alpha _ { j } ^ { 2 } + ( B _ { s } V ) ^ { 2 } } \left\{\alpha_{j} \sin \left(B_{s} l_{v}-\theta_{s}\right)\right.\right.
$$$$
+B_{s} V \cos \left(B_{s} l_{v}-\theta_{s}\right)
$$$$
-\exp \left(\alpha_{j} t\right)\left[\alpha_{j} \sin \left(B_{s}(l-V t)-\theta_{s}\right)\right.
$$$$
\left.\left.+B_{s} V \cos \left(B_{s}\left(l_{v}-V t\right)+\theta_{s}\right)\right]\right\}
$$$$
+\frac{4 h_{0} V \exp \left(-\alpha_{j} t\right)}{\alpha_{j}^{2} L^{2}}
$$$$
\times\left\{2 V\left[\exp \left(\alpha_{j} t\right)\left(\alpha_{j} t-1\right)+1\right]\right.
$$$$
\left.\left.-\alpha_{j}\left(2 l_{v}+L\right)\left(\exp \left(\alpha_{j} t\right)-1\right)\right\}\right] \text {. }
$$

The third term of (A.4) is written as

$$
I_{j y}=\sum_{k=1}^{n_{b}} I_{j_{n_{v}}+2+k} .
$$

The $k$ th term of the above series is composed of ten different terms as given below

$$
I_{j_{n_{v}}+2+k}=\sum_{a=1}^{10} I_{\left(j_{n_{v}}+2+k\right) a} \quad\left(k=1,2,3, \ldots, n_{b}\right) .
$$

The components of (A.11) are as follows: Introducing the following parameters:

$$
\begin{aligned}
& Q_{s}=B_{s} V ; \quad R_{k}=\frac{k \pi V}{L} ; \\
& S_{k}=\frac{k \pi}{L} ; \quad Z_{s}=B_{s} l_{v}, \\
& I_{(j n v+2+k)_{1}} \\
& =\frac{1}{2} k_{t 1} \sum_{s=1}^{N} A_{s}\left\{\left(\left(2 R_{k} \exp \left(-\alpha_{j} t\right)\right.\right.\right. \\
& \times\left\{\left(\alpha_{j}^{2}-Q_{s}^{2}+R_{k}^{2}\right) \cos \left(\theta_{s}\right)\right. \\
& \left.\left.+2 \alpha_{j} Q_{s} \sin \left(\theta_{s}\right)\right\}\right) \\
& \times\left(\left\{\alpha_{j}^{2}+\left(Q_{s}-R_{k}\right)^{2}\right\}\right. \\
& \left.\left.\times\left\{\alpha_{j}^{2}+\left(Q_{s}+R_{k}\right)^{2}\right\}\right)^{-1}\right) \\
& -\left(\left(\alpha_{j} \sin \left\{\left(Q_{s}-R_{k}\right) t+\theta_{s}\right\}\right.\right. \\
& +\left(R_{k}-Q_{s}\right) \\
& \left.\times \cos \left\{\left(Q_{s}-R_{k}\right) t+\theta_{s}\right\}\right) \\
& \left.\times\left(\left\{\alpha_{j}^{2}+\left(Q_{s}-R_{k}\right)^{2}\right\}\right)^{-1}\right) \\
& +\left(\left(\alpha_{j} \sin \left\{\left(Q_{s}+R_{k}\right) t+\theta_{s}\right\}\right.\right. \\
& -\left(R_{k}+Q_{s}\right) \\
& \left.\times \cos \left\{\left(Q_{s}+R_{k}\right) t+\theta_{s}\right\}\right) \\
& \left.\left.\times\left(\left\{\alpha_{j}^{2}+\left(Q_{s}+R_{k}\right)^{2}\right\}\right)^{-1}\right)\right\}, \\
& I_{(j n v+2+k)_{2}} \\
& =\frac{1}{2} k_{t 1}\left[\frac{4 h_{0} V \exp \left(-\alpha_{j} t\right)}{L^{2}\left(\alpha_{j}^{2}+Q_{s}^{2}\right)^{3}}\right. \\
& \times\left\{L ( \alpha _ { j } ^ { 2 } + Q _ { s } ^ { 2 } ) \left[\exp \left(\alpha_{j} t\right) \sin \left(Q_{s} t\right)\right.\right. \\
& \times\left\{Q_{s}^{2}\left(\alpha_{j} t+1\right)\right. \\
& \left.\left.+\alpha_{j}^{2}\left(\alpha_{j} t-1\right)\right\}\right] \\
& -Q_{s} \exp \left(\alpha_{j} t\right) \cos \left(Q_{s} t\right) \\
& \left.\times\left[Q_{s}^{2} t+\alpha_{j}\left(\alpha_{j} t-2\right)\right]-2 \alpha_{j} Q_{s}\right\} \\
& +V\left(2 Q_{s}^{3}+Q_{s} \exp \left(\alpha_{j} t\right)\right) \cos \left(Q_{s} t\right) \\
& \times\left\{Q_{s}^{4} t^{2}+2 Q_{s}^{2}\left(\alpha_{j}^{2} t^{2}-2 \alpha_{j} t-1\right)\right.
\end{aligned}
$$




$$
\begin{aligned}
& \left.+\alpha_{j}^{2}\left(\alpha_{j}^{2} t^{2}-4 \alpha_{j} t+6\right)\right\} \\
& -l_{v}\left(\alpha_{j}^{2}+V^{2}\right) \\
& -\exp \left(\alpha_{j} t\right) \sin \left(Q_{s} t\right) \\
& \times\left\{Q_{s}^{4}\left(\alpha_{j} t+2\right)+\alpha_{j} Q_{s}^{2}\left(\alpha_{j}^{2} t^{2}-3\right)\right. \\
& \left.\left.+\alpha_{j}^{3}\left(\alpha_{j}^{2} t^{2}-2 \alpha_{j} t+2\right)\right\}-6 \alpha_{j}^{2} Q_{s}\right], \\
& I_{(j n v+2+k)_{3}} \\
& =\frac{1}{2} k_{t 2} \sum_{s=1}^{N} A_{s}\left[\exp \left(-\alpha_{j} t\right)\right. \\
& \times\left\{\left(\left(\left(R_{k}+Q_{s}\right) \cos \left(S_{s}-Z_{s}-\theta_{s}\right)\right.\right.\right. \\
& \left.+\alpha_{j} \sin \left(S_{k}-Z_{s}-\theta_{s}\right)\right) \\
& \left.\times\left(\left\{\alpha_{j}^{2}+\left(Q_{s}-R_{k}\right)^{2}\right\}\right)^{-1}\right) \\
& \times\left(\left(\left(R_{k}-Q_{s}\right) \cos \left(S_{k}-Z_{s}+\theta_{s}\right)\right.\right. \\
& \left.+\alpha_{j} \sin \left(S_{k}-Z_{s}+\theta_{s}\right)\right) \\
& \left.\left.\times\left(\left\{\alpha_{j}^{2}+\left(Q_{s}-R_{s}\right)^{2}\right\}\right)^{-1}\right)\right\} \\
& -\left(\left(\alpha_{j} \sin \left\{\left(Q_{s}-R_{k}\right) t+S_{k}-Z_{s}+\theta_{s}\right\}\right.\right. \\
& -\left(R_{k}+Q_{s}\right) \cos \left\{\left(Q_{s}-R_{k}\right) t\right. \\
& \left.\left.+S_{k}-Z_{s}+\theta_{s}\right\}\right) \\
& \left.\times\left(\left\{\alpha_{j}^{2}+\left(Q_{s}-R_{s}\right)^{2}\right\}\right)^{-1}\right) \\
& +\left(\left(\alpha_{j} \sin \left\{S_{k}+Z_{s}-\left(Q_{s}+R\right) t-\theta_{s}\right\}\right.\right. \\
& +\left(R_{k}+Q_{s}\right) \cos \left\{S_{k}+Z_{s}\right. \\
& +\left(Q_{s}+R_{k}\right) t \\
& \left.\left.-\theta_{s}\right\}\right) \\
& \left.\left.\times\left(\left\{\alpha_{j}^{2}+\left(Q_{s}+R_{k}\right)^{2}\right\}\right)^{-1}\right)\right], \\
& I_{(j n v+2+k)_{4}} \\
& =-\frac{1}{2} k_{t 2}\left[\frac{4 h_{0} V}{L^{2}\left(\alpha_{j}^{2}+V^{2}\right)^{3}}\right. \\
& \times\left\{\operatorname { s i n } ( V t - l _ { v } ) \left\{\left[\alpha_{j} l_{v}^{2}\left(\alpha_{j}^{2}+V^{2}\right)^{2}\right.\right.\right. \\
& \times\left\{-\alpha_{j}^{3} L-\alpha_{j} L V^{2}\right. \\
& +2 V^{3}\left(\alpha_{j} t+1\right) \\
& \left.+2 \alpha_{j}^{2} V\left(\alpha_{j} t-1\right)\right\} \\
& +V\left[V \left\{2 \alpha_{j}^{3}+\alpha_{j} t\left(\alpha_{j}^{2}+V^{2}\right)^{2}\right.\right. \\
& \left.+2 t\left(\alpha_{j}^{4}-V^{4}\right)-6 \alpha_{j} V^{2}\right\} \\
& -L\left(\alpha_{j}^{2}+V^{2}\right) \\
& \left.\times\left\{\alpha_{j}^{2}\left(\alpha_{j} t-1\right)+V^{2}\left(\alpha_{j} t+1\right)\right\}\right] \\
& +V \cos \left(l_{v}-V t\right)\left[V ^ { 4 } \left(l_{v}^{2}+l_{v} L\right.\right. \\
& \left.+2 \alpha_{j}^{2} t^{2}-4 \alpha_{j} t-2\right) \\
& +\alpha_{j}^{2} V^{2}\left(2 l_{v}^{2}+2 l_{v} L\right. \\
& \left.+4 \alpha_{j}^{2} t^{2}+6\right) \\
& +\alpha_{j}^{4} l_{v}\left(l_{v}+L\right) \\
& -V^{5} t\left(2 l_{v}+L\right) \\
& \times\left(\alpha_{j} t-1\right) \\
& -\alpha_{j}^{3} V\left(2 l_{v}+L\right) \\
& \left.\left.\left.\times\left(\alpha_{j} t-2\right)+l_{v}^{2} V^{6}\right]\right\}\right] \\
& =\frac{1}{2} c_{t 1} \sum_{s=1}^{N} A_{s} Q_{s}\left\{\left(-\left(2 R_{k} \exp \left(-\alpha_{j} t\right)\right.\right.\right. \\
& \times\left\{\left(\alpha_{j}^{2}-Q_{s}^{2}+R_{k}^{2}\right) \sin \left(\theta_{s}\right)\right. \\
& \left.\left.-2 \alpha_{j} Q_{s} \cos \left(\theta_{s}\right)\right\}\right) \\
& \times\left(\left\{\alpha_{j}^{2}+\left(Q_{s}-R\right)^{2}\right\}\right. \\
& \left.\left.\times\left\{\alpha_{j}^{2}+\left(Q_{s}+R_{k}\right)^{2}\right\}\right)^{-1}\right) \\
& -\left(\left(\alpha_{j} \cos \left\{\left(Q_{s}-R_{k}\right) t+\theta_{s}\right\}\right.\right. \\
& +\left(R_{k}-Q_{s}\right) \\
& \left.\times \sin \left\{\left(Q_{s}-R_{k}\right) t+\theta_{s}\right\}\right)
\end{aligned}
$$




$$
\begin{aligned}
& \left.\times\left(\left\{\alpha_{j}^{2}+\left(Q_{s}+R_{k}\right)^{2}\right\}\right)^{-1}\right) \\
& +\left(\left(\alpha_{j} \cos \left\{\left(Q_{s}+R_{k}\right) t+\theta_{s}\right\}\right.\right. \\
& +\left(R_{k}+Q_{s}\right) \\
& \left.\times \sin \left\{\left(Q_{s}+R_{k}\right) t+\theta_{s}\right\}\right) \\
& \left.\left.\times\left(\left\{\alpha_{j}^{2}+\left(Q_{s}+R_{k}\right)^{2}\right\}\right)^{-1}\right)\right\} \\
& I_{(j n v+2+k)_{6}} \\
& =-c_{t 1} \frac{2 h_{0} V \exp \left(-\alpha_{j} t\right)}{L^{2}\left(\alpha_{j}^{2}+V^{2}\right)^{3}} \\
& \times\left\{\exp \left(\alpha_{j} t\right) \cos \left(Q_{s} t\right)\right. \\
& \times\left[Q_{s}^{2}\left(2 \alpha_{j} t V-\alpha_{j} L+2 V\right)\right. \\
& \left.+\alpha_{j}^{2}\left(2 \alpha_{j} t V-\alpha_{j} L-2 V\right)\right] \\
& -Q_{s} \exp \left(\alpha_{j} t\right) \sin \left(Q_{s} t\right) \\
& \times\left[Q_{s}^{2}(L-V t)\right. \\
& \left.\left.+\alpha_{j}\left(\alpha_{j} L-2 \alpha_{j} t V+4 V\right)\right]\right\}, \\
& I_{(j n v+2+k)_{7}} \\
& =\frac{1}{2} c_{t 2} \sum_{s=1}^{N} A_{s} Q_{s} \\
& \times\left[\operatorname { e x p } \left(-\alpha_{j} t\left\{\left(\left(\left(R_{k}+Q_{s}\right) \sin \left(S_{k}+Z_{s}-\theta_{s}\right)\right.\right.\right.\right.\right. \\
& \left.-\alpha_{j} \cos \left(S_{k}+Z_{s}-\theta_{s}\right)\right) \\
& \left.\times\left(\left\{\alpha_{j}^{2}+\left(Q_{s}-R_{k}\right)^{2}\right\}\right)^{-1}\right) \\
& \times\left(\left(\left(Q_{s}-R_{k}\right) \sin \left(S_{k}-Z_{s}+\theta_{s}\right)\right.\right. \\
& \left.+\alpha_{j} \cos \left(S_{k}-Z_{s}+\theta_{s}\right)\right) \\
& \left.\left.\times\left(\left\{\alpha_{j}^{2}+\left(Q_{s}-R\right)^{2}\right\}\right)^{-1}\right)\right\} \\
& +\left(\left(\alpha_{j} \cos \left\{S_{k}+Z_{s}-\left(Q_{s}+R_{k}\right) t-\theta_{s}\right\}\right.\right. \\
& -\left(R_{k}+Q_{s}\right) \sin \left\{S_{k}+Z_{s}\right. \\
& \left.\left.-\left(Q_{s}+R_{k}\right) t-\theta_{s}\right\}\right) \\
& \left.\times\left(\left\{\alpha_{j}^{2}+\left(Q_{s}+R_{k}\right)^{2}\right\}\right)^{-1}\right) \\
& \begin{array}{c}
-\left(\left(\alpha_{j} \cos \left\{S_{k}-Z_{s}+\left(Q_{s}-R_{k}\right) t+\theta_{s}\right\}\right.\right. \\
+\left(Q_{s}-R_{k}\right) \sin \left\{S_{k}-Z_{s}\right. \\
\left.\left.+\left(Q_{s}-R_{k}\right) t+\theta_{s}\right\}\right) \\
\left.\left.\times\left(\left\{\alpha_{j}^{2}+\left(Q_{s}-R_{k}\right)^{2}\right\}\right)^{-1}\right)\right],
\end{array} \\
& I_{(j n v+2+k)_{8}} \\
& =-c_{t 2} \frac{2 h_{0} V \exp \left(-\alpha_{j} t\right)}{L^{2}\left(\alpha_{j}^{2}+V^{2}\right)^{3}} \\
& \times\left\{\exp \left(\alpha_{j} t\right) \sin \left(Q_{s} t\right)\right. \\
& \times\left[Q_{s}^{2}\left(2 \alpha_{j} t V-\alpha_{j} L+2 V\right)\right. \\
& \left.+\alpha_{j}^{2}\left(2 \alpha_{j} t V-\alpha_{j} L-2 V\right)\right] \\
& -Q_{s} \exp \left(\alpha_{j} t\right) \cos \left(Q_{s} t\right) \\
& \times\left[Q_{s}^{2}(L-V t)\right. \\
& \left.\left.+\alpha_{j}\left(\alpha_{j} L-2 \alpha_{j} t V+4 V\right)\right]\right\}, \\
& I_{(j n v+2+k)_{9}} \\
& =-\frac{\exp \left(-\alpha_{j} t\right) g L\left(l_{v} m_{v}+2 m_{w 1}\right)}{2\left(L^{2} \alpha_{j}^{2}+n^{2} \pi^{2} V^{2}\right)} \\
& \times\left[k \pi V+\exp \left(\alpha_{j} t\right)\left\{k \pi V \cos \left(\frac{k \pi V t}{L}\right)\right.\right. \\
& \left.\left.+L \alpha_{j} \sin \left(\frac{k \pi V t}{L}\right)\right\}\right] \\
& -\frac{\exp \left(-\alpha_{j} t\right) g L\left(l_{v} m_{v}+2 m_{w 2}\right)}{2\left(L^{2} \alpha_{j}^{2}+n^{2} \pi^{2} V^{2}\right)} \\
& \times\left[k \pi V \left\{\cos \left(\frac{k \pi D}{L}\right)\right.\right. \\
& \left.-\exp \left(\alpha_{j} t\right) \cos \left(k \pi \frac{D-V t}{L}\right)\right\} \\
& -L \alpha_{j}\left\{\sin \left(\frac{k \pi D}{L}\right)\right. \\
& \left.\left.-\exp \left(\alpha_{j} t\right) \sin \left(k \pi \frac{D-V t}{L}\right)\right\}\right], \\
& I_{(j n v+2+k)_{10}}=-2 L V^{2}\left(m_{w 1}+m_{w 2}\right)
\end{aligned}
$$




$$
\begin{aligned}
& \times \sum_{s=1}^{N} A_{s} B_{s}^{2}\left[\left(\left(\left(k \pi-B_{s} L\right) V \cos \left[\left(Q_{s}-R_{s}\right) t+\theta_{s}\right]\right.\right.\right. \\
& \left.+L \alpha_{j} \sin \left[\left(Q_{s}-R_{s}\right) t+\theta_{s}\right]\right) \\
& \times\left(B_{s}^{2} L^{2} V^{2}-2 k \pi B_{s} L V^{2}\right. \\
& \left.\left.+k^{2} \pi^{2} V^{2}+L^{2} \alpha_{j}^{2}\right)^{-1}\right) \\
& -\left(\left(\left(k \pi+B_{s} L\right) V \cos \left[\left(Q_{s}+R_{s}\right) t+\theta_{s}\right]\right.\right. \\
& \left.+L \alpha_{j} \sin \left[\left(Q_{s}+R_{s}\right) t+\theta_{s}\right]\right) \\
& \times\left(B_{s}^{2} L^{2} V^{2}+2 k \pi B_{s} L V^{2}\right. \\
& \left.\left.+k^{2} \pi^{2} V^{2}+L^{2} \alpha_{j}^{2}\right)^{-1}\right) \\
& -\exp \left(-\alpha_{j} t\right)\left\{\left(\left(-\left(k \pi+B_{s} L\right) V \cos \theta_{s}\right.\right.\right. \\
& \left.+L \alpha_{j} \sin \theta_{s}\right) \\
& \times\left(B_{s}^{2} L^{2} V^{2}\right. \\
& +2 k \pi B_{s} L V^{2} \\
& +k^{2} \pi^{2} V^{2} \\
& \left.\left.+L^{2} \alpha_{j}^{2}\right)^{-1}\right) \\
& +\left(\left(k \pi-B_{s} L\right) V \cos \theta_{s}\right. \\
& \left.-L \alpha_{j} \sin \theta_{s}\right) \\
& \times\left(\left(k \pi-B_{s} L\right)^{2} V^{2}\right. \\
& \left.\left.\left.\left.+L^{2} \alpha_{j}^{2}\right)^{-1}\right)\right\}\right] \\
& -\frac{8 h_{0} V^{2}\left(m_{w 1}+m_{w 2}\right)}{k^{2} \pi^{2} V^{2}+L^{2} \alpha_{j}^{2}} \\
& \times[k \pi V \\
& \times\left\{\exp \left(-\alpha_{j} t\right)-\cos \left(\frac{k \pi V t}{L}\right)\right\} \\
& \left.+L \alpha_{j} \sin \left(\frac{k \pi V t}{L}\right)\right] .
\end{aligned}
$$

The fourth term of (A.4) is written as

$$
I_{j z}=\sum_{k=1}^{n_{t}} I_{j n_{v}+2+n_{b}+k}
$$

The $k$ th term of the above series, can be split up into ten parts as given below:

$$
I_{j n_{v}+2+n_{b}+l}=\sum_{a=1}^{10} I_{\left(j n_{v}+2+n_{b}+l\right)} \quad\left(k=1,2,3, \ldots, n_{T}\right) .
$$

The components of (A.14) are as follows:

$$
\begin{aligned}
& I_{\left(j n_{v}+2+n_{b}+l\right)_{1}} \\
& =-\frac{1}{2} k_{t 1} e_{x} \\
& \times \sum_{s=1}^{N} A_{s} \exp \left(-\alpha_{j} t\right) \\
& \times\left\{\frac{\alpha_{j} \cos \left(\theta_{s}\right)+\left(Q_{s}-R_{k}\right) \sin \left(\theta_{s}\right)}{\alpha_{j}^{2}+\left(Q_{s}-R_{k}\right)^{2}}\right. \\
& +\frac{\alpha_{j} \cos \left(\theta_{s}\right)+\left(Q_{s}+R_{k}\right) \sin \left(\theta_{s}\right)}{\alpha_{j}^{2}+\left(Q_{s}+R_{k}\right)^{2}} \\
& +\left(\left(\alpha_{j} \cos \left[\left(Q_{s}-R_{k}\right) t+\theta_{s}\right]\right.\right. \\
& \left.+\left(Q_{s}-R_{k}\right) \sin \left[\left(Q_{s}-R_{k}\right) t-\theta_{s}\right]\right) \\
& \left.\times\left(\alpha_{j}^{2}+\left(Q_{s}-R_{k}\right)^{2}\right)^{-1}\right) \\
& +\left(\left(\alpha_{j} \cos \left[\left(Q_{s}+R_{k}\right) t+\theta_{s}\right]\right.\right. \\
& \left.+\left(Q_{s}+R_{k}\right) \sin \left[\left(Q_{s}+R_{k}\right) t+\theta_{s}\right]\right) \\
& \left.\left.\times\left(\alpha_{j}^{2}+\left(Q_{s}+R_{k}\right)^{2}\right)^{-1}\right)\right\}, \\
& I_{\left(j n_{v}+2+n b+l\right)_{2}} \\
& =\frac{4 k_{t 1} e_{x} h_{0} L}{V\left(\alpha_{j}^{2}+R_{k}^{2}\right)^{3}} \\
& \times\left[\left(\alpha_{j}^{2}+R_{k}^{2}\right) \exp \left(-\alpha_{j} t\right)\right. \\
& \times\left\{\alpha_{j}^{2}+\exp \left(-\alpha_{j} t\right) \cos \left(R_{k} t\right)\right. \\
& \times\left[R_{k}^{2}\left(\alpha_{j} t+1\right)+\alpha_{j}^{2}\left(\alpha_{j} t-1\right)\right]
\end{aligned}
$$




$$
\begin{aligned}
& +R_{k} \exp \left(\alpha_{j} t\right) \sin \left(R_{k} t\right) \\
& I_{\left(j n_{v}+2+n b+l\right)_{4}} \\
& \left.\times\left[R_{k}^{2} t+\alpha_{j}\left(\alpha_{j} t-2\right)\right]-R_{k}^{2}\right\} \\
& =\frac{4 k_{t 2} e_{x} h_{0}}{L^{2}}\left[\left\{\left(\left(l_{v}\left(l_{v}+L\right) \exp \left(-\alpha_{j} t\right)\right.\right.\right.\right. \\
& +2 \alpha_{j} \exp \left(-\alpha_{j} t\right)\left(\alpha_{j}^{2}+3 R_{k}{ }^{2}\right) \\
& +R_{k} \sin \left(R_{k} t\right)\left\{6 \alpha_{j}^{2}+t^{2}\left(\alpha_{j}^{2}+R_{k}^{2}\right)^{2}\right. \\
& \left.+4 \alpha_{j} t\left(\alpha_{j}^{2}+R_{k}^{2}\right)-2 R_{k}^{2}\right\} \\
& +\cos \left(R_{k} t\right)\left\{2 t\left(R_{k}{ }^{4}-\alpha_{j}^{4}\right)\right. \\
& +2 \alpha_{j}\left(\alpha_{j}^{2}-3 R_{k}^{2}\right) \\
& \left.\left.\times \alpha_{j} t^{2}\left(\alpha_{j}^{2}+R_{k}^{2}\right)^{2}\right\}\right], \\
& \times\left\{\alpha_{j} \cos \left(S_{k}-R_{k} t\right)\right. \\
& \left.-R_{k} \sin \left(S_{k}-R_{k} t\right)\right\} \\
& \left.+R_{k} \sin (S)-\alpha_{j} \cos \left(S_{k}\right)\right) \\
& \left.\left.\times\left(\alpha_{j}^{2}+R_{k}^{2}\right)^{-1}\right)\right\} \\
& +\frac{2 L V \exp \left(-\alpha_{j} t\right)}{\left(\alpha_{j}^{2}+R_{k}^{2}\right)^{2}} \\
& \times\left\{\left(\alpha_{j}^{2}+R_{k}^{2}\right) \cos \left(S_{k}\right)\right. \\
& +\exp \left(\alpha_{j} t\right) \cos \left(S_{k}-R_{k} t\right) \\
& =-\frac{1}{2} k_{t 2} e_{x} \\
& \times \sum_{s=1}^{N}\left[A_{s} \exp \left(-\alpha_{j} t\right)\right. \\
& \times\left\{\left(\left(\alpha_{j} \cos \left(B_{s} l_{v}-S_{k}-\theta_{s}\right)\right.\right.\right. \\
& \left.+\left(R_{k}-Q_{s}\right) \sin \left(B_{s} l_{v}-S_{k}-\theta_{s}\right)\right) \\
& \left.\times\left(\alpha_{j}^{2}+\left(Q_{s}-R\right)^{2}\right)^{-1}\right) \\
& +\left(\left(\alpha_{j} \cos \left(B_{s} l_{v}+S_{k}-\theta_{s}\right)\right.\right. \\
& \left.+\left(R_{k}+Q_{s}\right) \sin \left(B_{s} l_{v}+S_{k}-\theta_{s}\right)\right) \\
& \left.\left.\times\left(\alpha_{j}^{2}+\left(Q_{s}+R_{k}\right)^{2}\right)^{-1}\right)\right\} \\
& +\left(\left(\alpha_{j} \cos \left[\left(R_{k}-Q_{s}\right) t+\left(B_{s} l_{v}-S_{k}-\theta_{s}\right)\right]\right.\right. \\
& +\left(R_{k}-Q_{s}\right) \sin \left[-\left(Q_{s}+R_{k}\right) t\right. \\
& \left.\left.+\left(B_{s} l_{v}+S_{k}-\theta_{s}\right)\right]\right) \\
& \left.\times\left(\alpha_{j}^{2}+\left(Q_{s}-R_{k}\right)^{2}\right)^{-1}\right) \\
& +\left(\left(\alpha _ { j } \operatorname { c o s } \left[-\left(R_{k}+Q_{s}\right) t\right.\right.\right. \\
& \left.+\left(B_{s} l_{v}+S_{k}-\theta_{s}\right)\right] \\
& -\left(R_{k}+Q_{s}\right) \sin \left[-\left(Q_{s}+R_{k}\right) t\right. \\
& \left.\left.+\left(B_{s} l_{v}+S_{k}-\theta_{s}\right)\right]\right) \\
& \left.\left.\times\left(\alpha_{j}^{2}+\left(Q_{s}+R_{k}\right)^{2}\right)^{-1}\right)\right], \\
& \times\left[R^{2}\left(\alpha_{j} t+1\right)+\alpha_{j}^{2}\left(\alpha_{j} t-1\right)\right] \\
& +R_{k}\left[R_{k}^{2} t+\alpha_{j}\left(\alpha_{j} t-2\right)\right] \\
& \left.\times \sin \left(S_{k}-R_{k} t\right)-2 \alpha_{j} R_{k} \sin \left(S_{k}\right)\right\} \\
& -\frac{V^{2}}{\left(\alpha_{j}^{2}+R_{k}^{2}\right)^{3}} \\
& \times\left\{R _ { k } \operatorname { s i n } ( S _ { k } - R _ { k } t ) \left[6 \alpha_{j}^{2}+t^{2}\left(\alpha_{j}^{2}+R_{k}^{2}\right)^{2}\right.\right. \\
& -4 \alpha_{j} t\left(\alpha_{j}^{2}+R_{k}^{2}\right) \\
& \left.-2 R_{k}^{2}\right] \\
& +2 \exp \left(-\alpha_{j} t\right) \\
& \times\left[\left(\alpha_{j}^{3}-3 \alpha_{j} R_{k}^{2}\right) \cos \left(S_{k}\right)\right. \\
& +R_{k}\left(R_{k}^{2}-3 \alpha_{j}^{2}\right) \\
& \left.\times \sin \left(S_{k}\right)\right] \\
& -\left[2 t\left(R_{k}^{4}-\alpha_{j}^{4}\right)+2 \alpha_{j}\left(\alpha_{j}^{2}-3 R_{k}^{2}\right)\right. \\
& \left.\left.\left.+\alpha_{j} t^{2}\left(\alpha_{j}^{2}+R_{k}^{2}\right)^{2}\right] \cos \left(S_{k}-R_{k} t\right)\right]\right\}, \\
& I_{\left(j n_{v}+2+n b+l\right)_{5}} \\
& =-\frac{1}{2} k_{t 1} e_{x} \\
& \times \sum_{s=1}^{N} A_{s} \exp \left(-\alpha_{j} t\right)
\end{aligned}
$$




$$
\begin{gathered}
\times\left\{\frac{\alpha_{j} \sin \left(\theta_{s}\right)+\left(Q_{s}-R_{k}\right) \cos \left(\theta_{s}\right)}{\alpha_{j}^{2}+\left(Q_{s}-R_{k}\right)^{2}}\right. \\
+\frac{\alpha_{j} \sin \left(\theta_{s}\right)-\left(Q_{s}+R_{k}\right) \cos \left(\theta_{s}\right)}{\alpha_{j}^{2}+\left(Q_{s}+R\right)^{2}} \\
+\left(\left(\alpha_{j} \sin \left[\left(Q_{s}-R_{k}\right) t+\theta_{s}\right]\right.\right. \\
\left.+\left(R_{k}-Q_{s}\right) \cos \left[\left(Q_{s}-R_{k}\right) t+\theta_{s}\right]\right) \\
\left.\quad \times\left(\alpha_{j}^{2}+\left(Q_{s}-R\right)^{2}\right)^{-1}\right) \\
+\left(\left(\alpha_{j} \sin \left[\left(Q_{s}+R_{k}\right) t+\theta_{s}\right]\right.\right. \\
\left.\quad-\left(Q_{s}+R\right) \sin \left[\left(Q_{s}+R_{k}\right) t+\theta_{s}\right]\right) \\
\left.\left.\times\left(\alpha_{j}^{2}+\left(Q_{s}+R_{k}\right)^{2}\right)^{-1}\right)\right\},
\end{gathered}
$$$$
\times\left\{R_{k}^{2}\left[\alpha_{j}\left(l_{v}+L\right)-2 V\left(\alpha_{j} t+1\right)\right]\right.
$$$$
\left.+\alpha_{j}^{2}\left[\alpha_{j}\left(l_{v}+L\right)+2 V\left(1-\alpha_{j} t\right)\right]\right\}
$$$$
+\exp \left(-\alpha_{j} t\right)\left\{R_{k} \sin \left(S_{k}\right)\right.
$$$$
\times\left[l_{v}\left(\alpha_{j}^{2}+R_{k}^{2}\right)\right.
$$$$
\left.+L\left(\alpha_{j}^{2}+R_{k}^{2}\right)+4 \alpha_{j} V\right]
$$$$
+\cos \left(S_{k}\right)
$$$$
\times\left[R_{k}^{2}\left\{2 V-\alpha_{j}\left(l_{v}+L\right)\right\}\right.
$$$$
-\alpha_{j}^{2}\left\{\alpha_{j}\left(l_{v}+L\right)\right.
$$$$
+2 V\}]\}] \text {, }
$$$$
\begin{array}{r}
I_{\left(j n_{v}+2+n b+l\right)_{8}} \\
=\frac{1}{2} c_{t 2} e_{x}
\end{array}
$$

$I_{\left(j n_{v}+2+n b+l\right)_{6}}$

$$
\begin{aligned}
& =\frac{4 c_{t 1} e_{x} h_{0} L}{\left(\alpha_{j}^{2}+R_{k}^{2}\right)^{3}}\left(\frac{V}{L}\right)^{2} \\
& \quad \times\left[\left(\alpha_{j}^{2}+R_{k}^{2}\right)\left\{\alpha_{j} \cos \left(R_{k} t\right)\right\}\right. \\
& \quad+R_{k} \sin \left(R_{k} t\right)-\alpha_{j} \exp \left(-\alpha_{j} t\right)
\end{aligned}
$$$$
\times \sum_{s=1}^{N}\left[A_{s} Q_{s} \exp \left(-\alpha_{j} t\right)\right.
$$$$
\times\left\{\left(\left(\alpha_{j} \cos \left(B_{s} l_{v}-S_{k}-\theta_{s}\right)\right.\right.\right.
$$$$
\left.+\left(Q_{s}-R_{k}\right) \sin \left(B_{s} l_{v}-S_{k}-\theta_{s}\right)\right)
$$$$
\left.\times\left(\alpha_{j}^{2}+\left(Q_{s}-R_{k}\right)^{2}\right)^{-1}\right)
$$$$
+2 \exp \left(-\alpha_{j} t\right)\left\{\alpha_{j}^{2}+\exp \left(\alpha_{j} t\right) \cos \left(R_{k} t\right)\right.
$$$$
\times\left[R_{k}^{2}\left(\alpha_{j} t+1\right)+\alpha_{j}^{2}\left(\alpha_{j} t-1\right)\right]
$$$$
+\left(\left(\alpha_{j} \sin \left(B_{s} l_{v}+S_{k}-\theta_{s}\right)\right.\right.
$$$$
+R_{k} \exp \left(\alpha_{j} t\right) \sin \left(R_{k} t\right)
$$$$
\times\left[R_{k}^{2} t+\alpha_{j}\left(\alpha_{j} t-2\right)\right]
$$$$
\left.\left.-R_{k}^{2}\right\}\right],
$$

$I_{\left(j n_{v}+2+n b+l\right)_{7}}$

$$
\begin{aligned}
& =\frac{4 c_{t 2} e_{x} h_{0}}{V\left(\alpha_{j}^{2}+R_{k}{ }^{2}\right)^{2}} \\
& \times\left[-R_{k} \sin \left(S_{k}-R_{k} t\right)\right. \\
& \quad \times\left\{l_{v}\left(\alpha_{j}^{2}+R_{k}{ }^{2}\right)+L\left(\alpha_{j}^{2}+R_{k}{ }^{2}\right)\right. \\
& \left.\quad-2 V\left[{R_{k}}^{2} t+\alpha_{j}\left(\alpha_{j} t-2\right)\right]\right\} \\
& +\cos \left(S_{k}-R_{k} t\right)
\end{aligned}
$$

$$
\begin{gathered}
\left.+\left(R_{k}+Q_{s}\right) \cos \left(B_{s} l_{v}+S_{k}-\theta_{s}\right)\right) \\
\left.\left.\times\left(\alpha_{j}^{2}+\left(Q_{s}+R_{k}\right)^{2}\right)^{-1}\right)\right\} \\
-\left(\left(\alpha _ { j } \operatorname { s i n } \left[\left(R-Q_{s}\right) t\right.\right.\right. \\
\left.+\left(B_{s} l_{v}-S_{k}-\theta_{s}\right)\right] \\
+\left(Q_{s}-R_{k}\right) \cos \left[\left(R_{k}-Q_{s}\right) t\right. \\
\left.\left.+\left(B_{s} l_{v}-S_{k}-\theta_{s}\right)\right]\right) \\
\left.\times\left(\alpha_{j}^{2}+\left(Q_{s}-R_{k}\right)^{2}\right)^{-1}\right) \\
-\left(\left(\alpha _ { j } \operatorname { s i n } \left[-\left(R+Q_{s}\right) t\right.\right.\right. \\
\left.+\left(B_{s} l_{v}+S_{k}-\theta_{s}\right)\right] \\
+\left(R_{k}+Q_{s}\right) \cos \left[-\left(Q_{s}+R_{k}\right) t\right. \\
\left.\left.+\left(B_{s} l_{v}+S_{k}-\theta_{s}\right)\right]\right)
\end{gathered}
$$




$$
\left.\left.\times\left(\alpha_{j}^{2}+\left(Q_{s}+R_{k}\right)^{2}\right)^{-1}\right)\right],
$$

$I_{\left(j n_{v}+2+n b+l\right)_{9}}$

$$
\begin{gathered}
=-e_{x} \frac{\exp \left(-\alpha_{j} t\right) g L\left(l_{v} m_{v}+2 m_{w 1}\right)}{2\left(L^{2} \alpha_{j}^{2}+n^{2} \pi^{2} V^{2}\right)} \\
\times\left[\exp \left(\alpha_{j} t\right) k \pi V \sin \left(\frac{k \pi V t}{L}\right)\right. \\
\left.-L \alpha_{j}+\exp L \alpha_{j}\left(\alpha_{j} t\right) \cos \left(\frac{k \pi V t}{L}\right)\right] \\
-e_{x} \frac{\exp \left(-\alpha_{j} t\right) g L\left(l_{v} m_{v}+2 m_{w 2}\right)}{2\left(L^{2} \alpha_{j}^{2}+n^{2} \pi^{2} V^{2}\right)} \\
\times\left[k \pi V \left\{\sin \left(\frac{k \pi D}{L}\right)\right.\right. \\
\left.-\exp \left(\alpha_{j} t\right) \sin \left(k \pi \frac{D-V t}{L}\right)\right\} \\
-e_{x} L \alpha_{j}\left\{\cos \left(\frac{k \pi D}{L}\right)\right. \\
\times \exp \left(\alpha_{j} t\right) \\
\left.\times \cos \left(k \pi \frac{D-V t}{L}\right)\right\}
\end{gathered}
$$$$
I_{\left(j n_{v}+2+n b+l\right)_{10}}=-2 L V^{2}\left(m_{w 1}+m_{w 2}\right) e_{x}
$$$$
\times \sum_{s=1}^{N} A_{s} B_{s}^{2}\left[\left(\left(\left(k \pi-B_{s} L\right) V \cos \left[\left(Q_{s}-R_{s}\right) t+\theta_{s}\right]\right.\right.\right.
$$$$
\left.+L \alpha_{j} \sin \left[\left(Q_{s}-R_{s}\right) t+\theta_{s}\right]\right)
$$$$
\times\left(B_{s}^{2} L^{2} V^{2}-2 k \pi B_{s} L V^{2}\right.
$$$$
\left.\left.+k^{2} \pi^{2} V^{2}+L^{2} \alpha_{j}^{2}\right)^{-1}\right)
$$$$
-\left(\left(\left(k \pi+B_{s} L\right) V\right.\right.
$$$$
\times \cos \left[\left(Q_{s}+R_{s}\right) t+\theta_{s}\right]
$$$$
\left.+L \alpha_{j} \sin \left[\left(Q_{s}+R_{s}\right) t+\theta_{s}\right]\right)
$$$$
\times\left(B_{s}^{2} L^{2} V^{2}+2 k \pi B_{s} L V^{2}\right.
$$$$
\left.\left.+k^{2} \pi^{2} V^{2}+L^{2} \alpha_{j}^{2}\right)^{-1}\right)
$$$$
-\exp \left(-\alpha_{j} t\right)
$$$$
\times\left\{\left(\left(-\left(k \pi+B_{s} L\right) V \cos \theta_{s}+L \alpha_{j} \sin \theta_{s}\right)\right.\right.
$$

$$
\times\left(B_{s}^{2} L^{2} V^{2}+2 k \pi B_{s} L V^{2}\right.
$$

$$
\begin{gathered}
\left.\left.+k^{2} \pi^{2} V^{2}+L^{2} \alpha_{j}^{2}\right)^{-1}\right) \\
+\left(\left(\left(k \pi-B_{s} L\right) V \cos \theta_{s}-L \alpha_{j} \sin \theta_{s}\right)\right. \\
\left.\left.\times\left(\left(k \pi-B_{s} L\right)^{2} V^{2}+L^{2} \alpha_{j}^{2}\right)^{-1}\right)\right] \\
-\frac{8 h_{0} V^{2} e_{x}\left(m_{w 1}+m_{w 2}\right)}{k^{2} \pi^{2} V^{2}+L^{2} \alpha_{j}^{2}} \\
\times\left[k \pi V\left\{\exp \left(-\alpha_{j} t\right)-\cos \left(\frac{k \pi V t}{L}\right)\right\}\right. \\
\left.+L \alpha_{j} \sin \left(\frac{k \pi V t}{L}\right)\right] .
\end{gathered}
$$

\section{Conflict of Interests}

The authors declare that there is no conflict of interests regarding the publication of this paper.

\section{References}

[1] L. Fryba, Vibration of Solids and Structures under Moving Loads, Noordhoff International, Groningen, The Netherlands, 1968.

[2] Y. B. Yang, J. D. Yau, and Y. S. Wu, Vehicle Bridge Interaction Dynamics with Application to High Speed Railways, World Scientific, 2004.

[3] J. M. Biggs, Introduction to Structural Dynamics, McGraw-Hill, NewYork, NY, USA, 1964.

[4] L. Fryba, Dynamics of Railway Bridges, Thomas Telford, Prague, Czech Republic, 1996.

[5] R. K. Wen, "Dynamic response of beams traversed by two axle loads," Journal of Engineering Mechanics Division, ASCE, vol. 86, pp. 91-111, 1960.

[6] D. Yadav and H. C. Upadhyay, "Heave-pitch-roll dynamics of a vehicle with a variable velocity over a non-homogeneously profiled flexible track," Journal of Sound and Vibration, vol. 164, no. 2, pp. 337-348, 1993.

[7] T. L. Wang, M. Shahawy, and D. Z. Huang, "Dynamic response of highway trucks due to road surface roughness," Journals of Computer and Structures, vol. 49, no. 6, pp. 1055-1067, 1993.

[8] J.-W. Kou and J. T. de Wolf, "Vibrational behavior of continuous span highway bridge-influencing variables," Journal of Structural Engineering, ASCE, vol. 123, no. 3, pp. 333-344, 1997.

[9] Y. K. Cheung, F. T. K. Au, D. Y. Zheng, and Y. S. Cheng, "Vibration of multi-span non-uniform bridges under moving vehicles and trains by using modified beam vibration functions," Journal of Sound and Vibration, vol. 228, no. 3, pp. 611-628, 1999.

[10] S. Marchesiello, A. Fasana, L. Garibaldi, and B. A. D. Piombo, "Dynamics of multi-span continuous straight bridges subject to multi-degrees of freedom moving vehicle excitation," Journal of Sound and Vibration, vol. 224, no. 3, pp. 541-561, 1999.

[11] X. Yin, Z. Fang, and C. S. Cai, "Lateral vibration of highpier bridges under moving vehicular loads," Journal of Bridge Engineering, vol. 16, no. 3, pp. 400-412, 2011.

[12] S. R. Chen and C. S. Cai, "Accident assessment of vehicles on long-span bridges in windy environments," Journal of Wind 
Engineering and Industrial Aerodynamics, vol. 92, no. 12, pp. 991-1024, 2004.

[13] S. S. Law and X. Q. Zhu, "Bridge dynamic responses due to road surface roughness and braking of vehicle," Journal of Sound and Vibration, vol. 282, no. 3-5, pp. 805-830, 2005.

[14] Y. Zhang, C. S. Cai, X. Shi, and C. Wang, "Vehicle-induced dynamic performance of FRP versus concrete slab bridge," Journal of Bridge Engineering, vol. 11, no. 4, pp. 410-419, 2006.

[15] M. F. Green and D. Cebon, "Dynamic interaction between heavy vehicles and highway bridges," Computers and Structures, vol. 62, no. 2, pp. 253-264, 1997.

[16] S. Marchesiello, A. Fasana, L. Garibaldi, and B. A. D. Piombo, "Dynamics of multi-span continuous straight bridges subject to multi-degrees of freedom moving vehicle excitation," Journal of Sound and Vibration, vol. 224, no. 3, pp. 541-561, 1999.

[17] K. H. Chu, V. K. Garg, and T. L. Wang, "Impact in railway prestressed concrete bridges," Journals of Structural Engineering, ASCE, vol. 112, no. 5, pp. 1036-1051, 1986.

[18] D. Huang, T.-L. Wang, and M. Shahawy, "Impact analysis of continuous multigirder bridges due to moving vehicles," Journals of Structural Engineering, ASCE, vol. 118, no. 12, pp. 3427-3443, 1992.

[19] T.-L. Wang, "Dynamic response of multigirder bridges," Journals of Structural Engineering, ASCE, vol. 118, no. 8, pp. 22222238, 1992.

[20] M. Ichikawa, Y. Miyakawa, and A. Matsuda, "Vibration analysis of the continuous beam subjected to a moving mass," Journal of Sound and Vibration, vol. 230, no. 3, pp. 493-506, 2000.

[21] N. H. Galdos, D. R. Schelling, and M. A. Sahin, "Methodology for impact factor of horizontally curved box bridges," Journals of Structural Engineering, ASCE, vol. 119, no. 6, pp. 1917-1934, 1993.

[22] Y. B. Yang, C. M. Wu, and J. D. Yau, "Dynamic response of a horizontally curved beam subjected to vertical and horizontal moving loads," Journal of Sound and Vibration, vol. 242, no. 3, pp. 519-537, 2001.

[23] H. Kishan and R. W. Traill-Nash, "A model method for calculation of highway bridge response with vehicle braking," Civil Engineering Transactions, Institute Engineers, Australia, vol. 19, no. 1, pp. 44-50, 1977.

[24] K. G. Radley and R. W. Traill-Nash, "Dynamic loading of highway bridges," Journal of Engineering Mechanics ASCE, vol. 106, no. 4, pp. 641-658, 1980.

[25] S. S. Law and X. Q. Zhu, "Bridge dynamic responses due to road surface roughness and braking of vehicle," Journal of Sound and Vibration, vol. 282, no. 3-5, pp. 805-830, 2005.

[26] P. Lou, "A vehicle-track-bridge interaction element considering vehicle's pitching effect," Finite Elements in Analysis and Design, vol. 41, no. 4, pp. 397-427, 2005.

[27] S. P. Brady, E. J. O’Brien, and A. Žnidarič, "Effect of vehicle velocity on the dynamic amplification of a vehicle crossing a simply supported bridge," Journal of Bridge Engineering, ASCE, vol. 11, no. 2, pp. 241-249, 2006.

[28] J.-D. Yau and Y.-B. Yang, "A wideband MTMD system for reducing the dynamic response of continuous truss bridges to moving train loads," Engineering Structures, vol. 26, no. 12, pp. 1795-1807, 2004.

[29] N. K. Harris, E. J. Obrien, and A. González, "Reduction of bridge dynamic amplification through adjustment of vehicle suspension damping," Journal of Sound and Vibration, vol. 302, no. 3, pp. 471-485, 2007.
[30] W. V. Wedig, "Digital simulation of roadvehicle systems," Probabilistic Engineering Mechanics, vol. 27, no. 1, pp. 82-87, 2012.

[31] S. Q. Wu and S. S. Law, "Evaluating the response statistics of an uncertain bridgevehicle system," Mechanical Systems and Signal Processing, vol. 27, no. 1, pp. 576-589, 2012.

[32] I. Kozar and N. T. Malic, "Spectral method in realistic modeling of bridges under moving vehicles," Engineering Structures, vol. 50, pp. 149-157, 2013.

[33] H. A. Nasrellah and C. S. Manohar, "A particle filtering approach for structural system identification in vehicle-structure interaction problems," Journal of Sound and Vibration, vol. 329, no. 9, pp. 1289-1309, 2010.

[34] M. Shinozuka, "Simulation of multivariate and multidimensional random process," Journal of Accoustical Society of America, vol. 49, pp. 357-367, 1971.

[35] D. Huang and T.-L. Wang, "Impact analysis of cable-stayed bridges," Computers and Structures, vol. 43, no. 5, pp. 897-908, 1992.

[36] D. H. Hodges and G. A. Pierce, Introduction to Structural Dynamics and Aero-Elasticity, Cambridge Aerospace Series, 2002.

[37] D. J. Inman, Engineering Vibration, Prentice Hall, 2001.

[38] N. C. Nigam, Introduction to Random Vibrations, The MIT Press, Cambridge, Mass, USA, 1983.

[39] M. C. Potter and J. Goldberg, Mathematical Methods, Prentice Hall, New Delhi, India, 1991.

[40] S. S. Rao, Mechanical Vibrations, Pearson, 4th edition, 2004.

[41] L. Deng and C. S. Cai, "Identification of parameters of vehicles moving on bridges," Journal of Engineering Structures, vol. 31, no. 10, pp. 2474-2485, 2009.

[42] ISO, 8606:1995, Mechanical vibration-Road surface profilesreporting measured data.

[43] E. S. Hwang and S. A. Nowak, "Simulation of dynamic load for bridges," Journal of Structural Engineering, ASCE, vol. 117, pp. 1413-1434, 1991. 

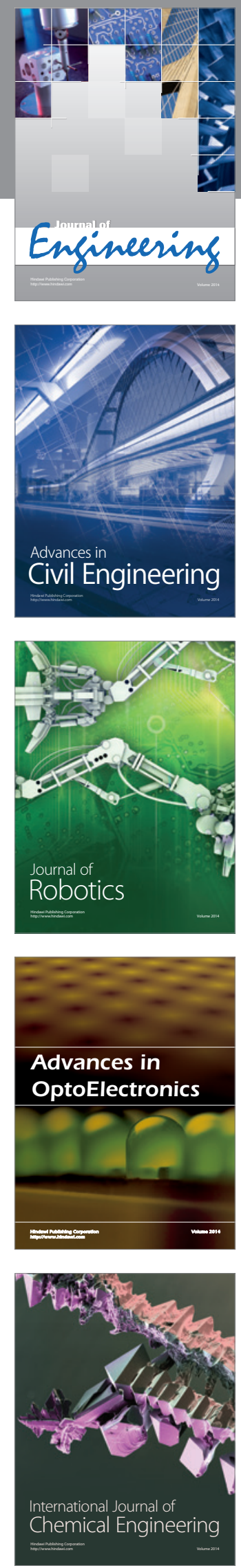

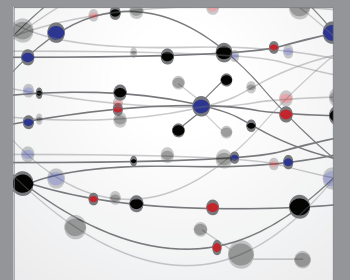

The Scientific World Journal
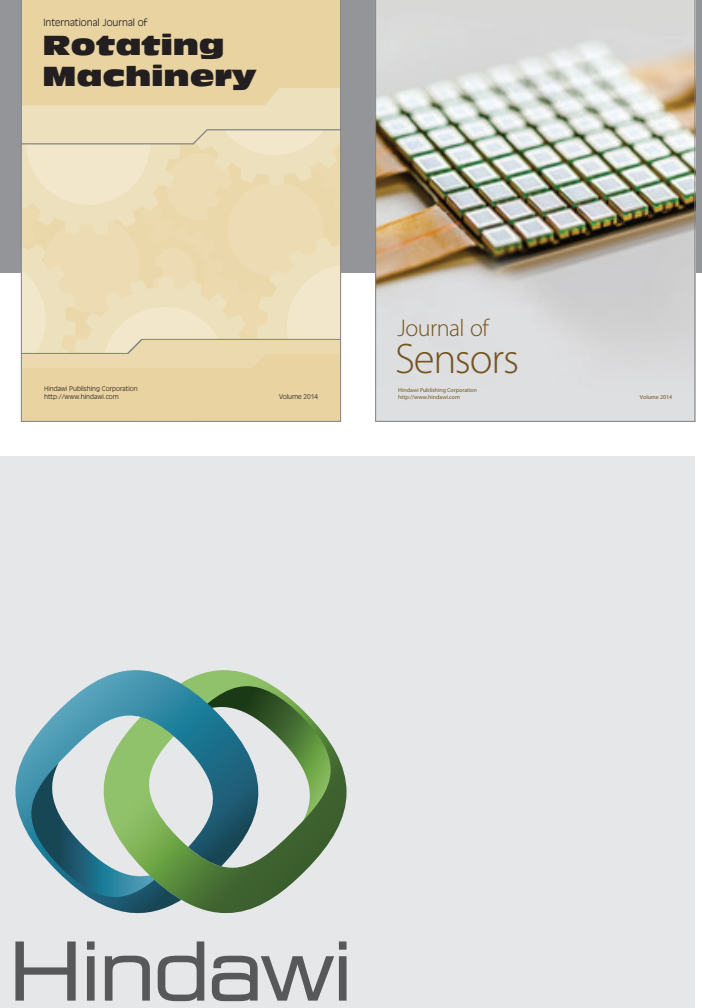

Submit your manuscripts at http://www.hindawi.com
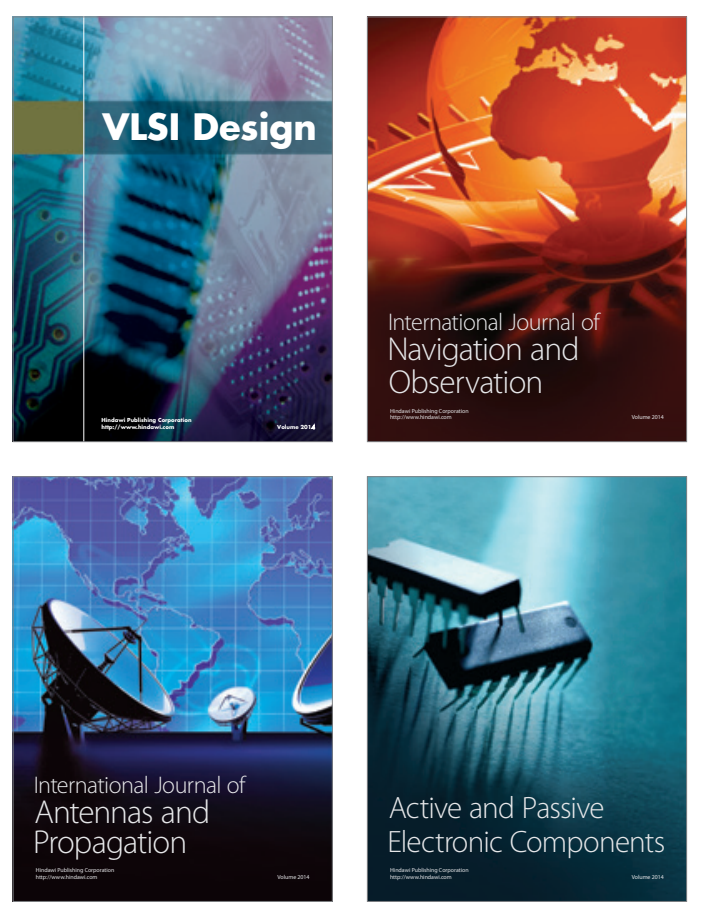
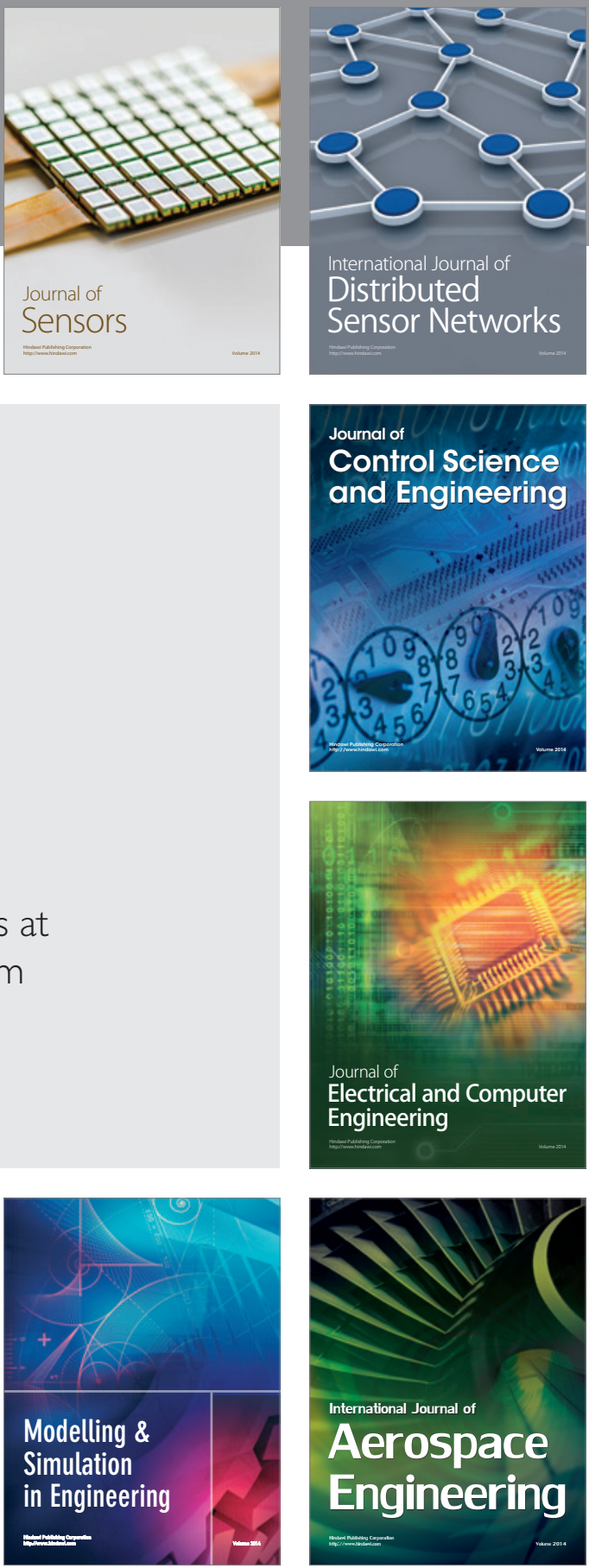

Journal of

Control Science

and Engineering
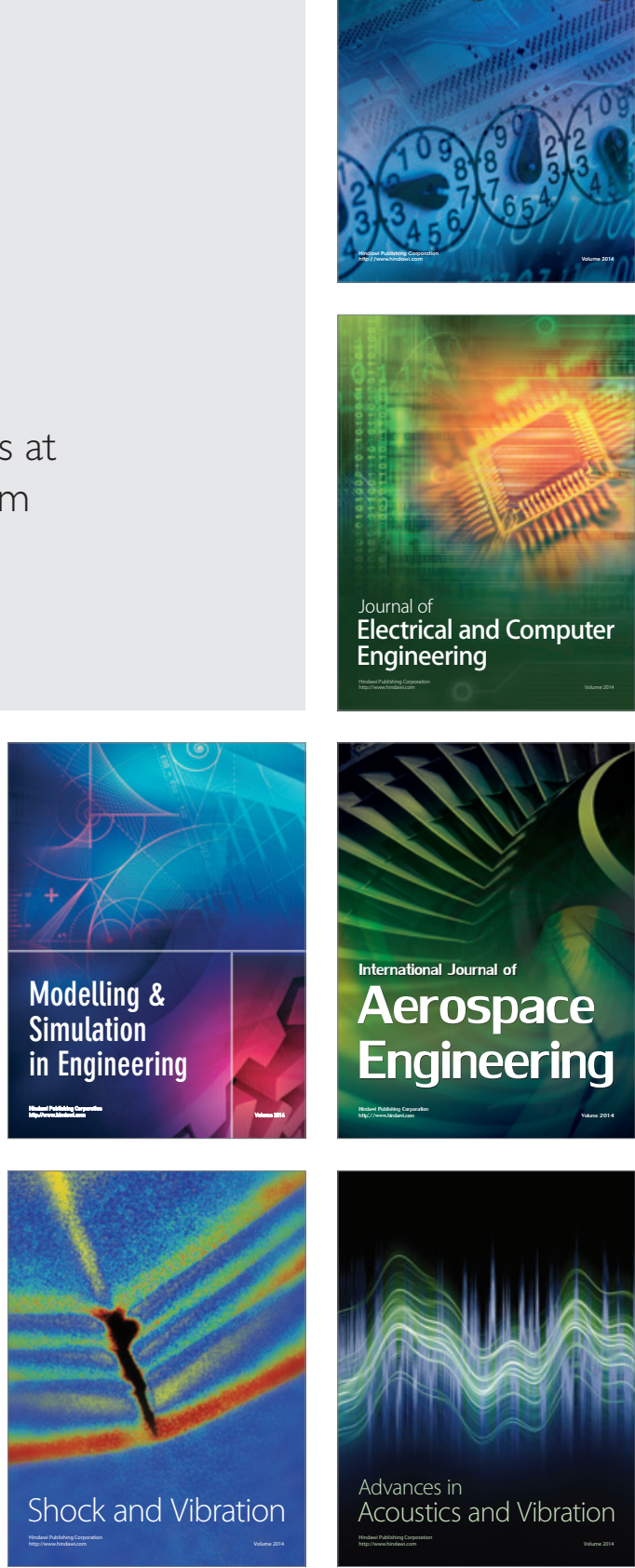